\title{
DO MINIMUM WAGES REDUCE EMPLOYMENT IN DEVELOPING COUNTRIES? A SURVEY AND EXPLORATION OF CONFLICTING EVIDENCE
}

\author{
David Neumark \\ Luis Felipe Munguia Corella \\ Working Paper 26462 \\ http://www.nber.org/papers/w26462
}

\author{
NATIONAL BUREAU OF ECONOMIC RESEARCH \\ 1050 Massachusetts Avenue \\ Cambridge, MA 02138 \\ November 2019
}

We are grateful for helpful comments from Haroon Bhorat, Stijn Broecke, Ravi Kanbur, Marieke Vandeweyer, seminar participants at Beijing Normal University, Renmin University, and DIWBerlin, and anonymous reviewers. The views expressed herein are those of the authors and do not necessarily reflect the views of the National Bureau of Economic Research.

NBER working papers are circulated for discussion and comment purposes. They have not been peerreviewed or been subject to the review by the NBER Board of Directors that accompanies official NBER publications.

(C) 2019 by David Neumark and Luis Felipe Munguia Corella. All rights reserved. Short sections of text, not to exceed two paragraphs, may be quoted without explicit permission provided that full credit, including $(\odot$ notice, is given to the source. 
Do Minimum Wages Reduce Employment in Developing Countries? A Survey and Exploration of Conflicting Evidence

David Neumark and Luis Felipe Munguia Corella

NBER Working Paper No. 26462

November 2019, Revised August 2020

JEL No. J18,J23,O15

\begin{abstract}
Evidence from studies of the employment effects of minimum wages in developing countries is mixed. One interpretation is that there is simply no clear evidence of disemployment effects in developing countries. Instead, however, we find evidence that the heterogeneity is systematic, with estimated effects more consistently negative in studies with relatively more features for which institutional factors and the competitive model more strongly predict negative effects. These features include whether studies:(i) focus on vulnerable workers; (ii) use data for the formal sector; (iii) cover countries where minimum wage laws are strongly enforced; and (iv) estimate effects for countries and periods with binding minimum wages.
\end{abstract}

David Neumark

Department of Economics

University of California, Irvine

3151 Social Science Plaza

Irvine, CA 92697

and NBER

dneumark@uci.edu

Luis Felipe Munguia Corella

Department of Economics

University of California, Irvine

3151 Social Science Plaza

Irvine, CA 92697

lfmungui@uci.edu 


\section{Introduction}

Minimum wages have been a controversial subject among policymakers and economists in the United States and many other countries. ${ }^{1}$ The evidence on employment effects in developing countries is quite mixed. In the studies we survey in this paper, simple averaging of all of the reported estimates yields a fairly modest negative employment elasticity of -0.061 , and averaging the authors' preferred estimates from each study yields an elasticity of -0.102 . However, looking across all the studies reveals considerable heterogeneity, with many negative estimates (some substantially larger in absolute value than these averages) but also many (although fewer) positive estimates.

The goal of our analysis is to examine the evidence from the large set of studies we survey, to try to understand this heterogeneous evidence and what we can learn from it. Is there simply no consistent evidence of negative employment effects of minimum wages in developing countries? That is, do we get heterogeneous effects - with both positive and negative estimates - even when studies are similar in looking at workers likely to be affected by minimum wages both because of their skills and because of the nature of a country's minimum wage law? Or, instead, is the heterogeneity in estimated minimum wage effects more systematic, with negative effects where we would expect them - e.g., for vulnerable low-skill workers where minimum wage laws are strong and binding - but not for higher-skill workers or where minimum wages laws are weaker and/or less binding?

We pursue these questions by conducting a version of a meta-analysis of a large set of studies of minimum wage effects in developing countries. Our focus is on understanding the differences in estimated employment effects across studies, which contrasts with the more common foci of meta-analyses on arriving at a single estimate from a body of studies and on publication bias (e.g., Belman and Wolfson, 2019; Broecke et al., 2016). Our analysis also contrasts with general surveys of the evidence for developing countries (Belman and Wolfson, 2016; Bhorat et al., 2017). Still, there are clearly complementarities between our approach and that of other surveys or meta-analyses.

It is important to consider how to interpret our evidence. There are three important points. First, stronger and more consistent evidence of adverse employment effects under conditions where we would 
expect adverse effects - e.g., for less-skilled workers, when minimum wages are binding or strongly enforced, or in the formal sector - would not negate the fact that estimated employment effects in developing countries vary. But such evidence would be informative about the institutional settings and contexts in which minimum wages reduce employment - such as when they are imposed in the formal sector and are strongly enforced.

Second, such evidence could indicate that minimum wages have more adverse consequences when they have the greatest potential benefits - i.e., for low-skilled workers for whom they are effective at raising wages. Of course, evidence that minimum wages reduce employment of lower-skilled workers does not imply that minimum wages are the wrong policy choice. However, such evidence would imply that minimum wages in developing countries reflect more of a tradeoff between higher wages and lower employment than what one might conclude from a simple overview of the heterogeneous evidence.

Ultimately, we think the wisdom of higher wages in developing countries should hinge more on whether they help raise incomes of low-income families. ${ }^{2}$

And third, this kind of evidence may speak to the right model of the labor market to use in thinking about labor market policy and other questions in developing countries. If evidence on employment effects of minimum wages is inconsistent for studies of less-skilled workers, in the formal sector, when minimum wages are binding and enforced, then it is possible that the monopsony model may better explain the evidence than the competitive model. ${ }^{3}$ In contrast, consistent evidence of disemployment effects in studies meeting these criteria, despite less consistent evidence in studies where negative employment effects are less likely to arise, would bolster the competitive characterization of labor markets (although it could still be possible to reconcile such evidence with monopsony).

We conclude that one can draw firmer conclusions about the employment effects of minimum wages in developing countries than first meets the eye when simply looking at all the estimates. We find that the estimated employment effects of minimum wages in developing countries are more likely to be negative, and larger negative, when estimates focus on data and sectors for which the competitive model predicts disemployment effects, and in institutional settings in which we would expect the minimum wage 
to have more adverse impact. Specifically, there is more consistent evidence of negative employment effects when the minimum wage is binding, where minimum wage enforcement is stronger, for estimates of effects in the formal sector, and when the data focus on more vulnerable (lower-wage) workers.

One dimension we do not explore is whether monopsony power is sometimes relevant. We do find that positive estimates are more prevalent in studies with only one feature or no features for which the competitive model and institutional factors predict negative effects. Monopsony is a potential explanation, but not the only one; for example, the standard two-sector competitive model predicts positive employment effects in the informal sector.

\section{Meta-Analysis in the Context of Minimum Wages Studies}

Meta-analysis developed as a method of combining results from existing studies, to derive conclusions from a body of research on a particular question or effect. In medicine, for example, early meta-analyses studied the evidence from randomized, controlled clinical trials, addressing the problem that individual medical studies sometimes lack enough observations to reach reliable statistical conclusions about the effect of the treatment studied. A meta-analysis pooling the evidence across studies can yield a more precise estimate of the impact of treatment, or other outcomes, than individual studies contributing to the pooled analysis. The technique was also applied, in the middle of the last century, to research in agricultural science, psychology, education, and sociology, although the term "meta-analysis" was apparently coined by Gene Glass in 1976, who described it as "analysis of analyses." (See the history of meta-analysis described Hunt, 1997).

Meta-analyses in economics also pool results, often in meta-regressions used to estimate an average effect (or treatment) size, and sometimes to estimate the impact of study features on the estimated effect size. Economists have been quite concerned with "publication bias," which considers the possibility

that some results are not published because of editors' and reviewers' (and perhaps authors') prior views, or because of diminished interest in statistically insignificant results, either of which can lead to bias in average estimates based on published work. Economists using meta-analysis also consider some of the more conventional problems that can arise in regression models - such as heteroskedasticity resulting from 
variation in precision of estimates across different studies owing to sample sizes or empirical strategies.

These same questions carry over to meta-analysis in the minimum wage literature. These analyses have pooled results to obtain estimates of the effect size - typically the magnitude of the elasticity of employment to the minimum wage. They have also been used to test for publication bias, and to try to interpret and systematize results that vary across studies done using different techniques, different data, or estimating effects for different groups. Our work in this paper is most closely related to meta-analyses that try to identify what features of studies explain heterogeneity of the estimated effects. ${ }^{4}$ For instance, Card and Krueger (1995) conduct a meta-analysis of time-series studies of the effect of the minimum wage on teen employment in the United States, and conclude that it is very likely that the results are affected by publication bias, induced by editors' and authors' tendencies to look for negative and significant estimates of the employment effects of the minimum wage, a conclusion shared by Doucouliagos and Stanley (2009), who also conclude that there is little or no evidence of a negative effect of the minimum wage once one corrects for publication bias. In contrast, Neumark and Wascher (2007) find that the results of published time-series studies of minimum wage effects are consistent with structural change and that the evidence does not reject the null hypothesis of no publication bias. The most recent meta-analysis of the minimum wage literature (Belman and Wolfson, 2019), based on newer studies that tend to use panel data with subnational minimum wage variation, finds little effect of publication bias and more evidence of minimum wage-employment elasticities for teens and other low-skill groups of around -0.1. And a smaller metaanalysis of studies of emerging economies (Broecke et al., 2017) finds more evidence of publication bias.

Our analysis is, in a sense, a meta-analysis, in that it is, to quote Glass, and "analysis of analyses." In particular, we conduct a version of a meta-analysis of a large set of studies of minimum wage effects in developing countries. However, in contrast to the main focus of meta-analyses of the minimum wage on questions like publication bias, or arriving at a single estimates from a body of studies (e.g., Belman and Wolfson, 2019; and Broecke et al., 2016), and also in contrast to general surveys of the evidence (e.g., Belman and Wolfson, 2016; Bhorat et al., 2017), our focus is explicitly on understanding the differences in estimated employment effects across studies. ${ }^{5}$ Some meta-analyses do study sources of variation in 
estimated effects. In particular, Belman and Wolfson (2016) is a broad survey of the effects of minimum wages on many different outcomes, and does not - in contrast to the present paper - focus on reconciling conflicting evidence, but more on issues of empirical methods. Broecke et al. (2017) use a meta-analysis to analyze 14 emerging economies, and present some evidence on differences for vulnerable workers and the formal sector. But both studies, as well as Doucouliagos and Stanley (2009), focus in large part on estimating the overall effect of the minimum wage on employment, and on publication bias.

We have some criticisms of using meta-analysis to study these questions with regard to the minimum wage literature (see Neumark, 2016). First, it is very hard to distinguish between publication bias and other sources of patterns in the published evidence consistent with publication bias. For example, metaanalyses like Doucouliagos and Stanley's argue that if published negative estimates of minimum wage effects have larger standard errors, this is evidence of publication bias. However, the same phenomenon can arise if studies using better research designs lead to "truer" estimates, which happen to be negative, but also have larger standard errors because the research designs demand more of the data. Second, averaging across estimates from studies of minimum wage effects, as meta-analyses do, is problematic. The populations studied vary, and this and other factors can influence how binding the minimum wage is, generating variation in estimated effects that there is no reason to simply average. For example, Neumark and Wascher (2007) show that studies more sharply focused on workers most likely to be affected by minimum wage increases reveal clearer evidence of disemployment effects. Among other factors potentially influencing the magnitude of the effect is of course how binding the minimum wage is, which may not be captured well in a standard regression framework (Neumark and Wascher, 2002). In short, the meta-analysis "paradigm" for combining estimates from many similar studies - say, randomized trials of a drug (Hunt, 1997) - carries over poorly to the minimum wage literature (and likely many other literatures in economics), although it can still be useful in identifying features of studies that lead to differences in estimates.

Because of these issues, our analysis does not follow the usual meta-regression approach of estimating average effects and testing for publication bias, although we do estimate some meta-regressions 
to help interpret our data by estimating relevant conditional differences across studies. Rather, we summarize, in a variety of ways, how estimated minimum wage effects vary based on features of the studies we examine. In particular, we summarize how the results vary with the inclusion of different study features among those that more strongly predict negative employment effects, and different combinations of them. We do not embed this analysis in a single meta-regression capturing all combinations of study features, because we are simultaneously considering study features that can exist in very many different combinations. But by considering the evidence on different combinations of study features, we go beyond the usual meta-regressions used in the minimum wage literature, which do not study combinations of study features at all (Belman and Wolfson, 2019; Broeke et al., 2017). Moreover, in terms of the substantive question we ask, our focus on differences across developing-country studies in features for which the competitive model and institutional factors are more likely (or not) to predict negative employment effects is, to the best of our knowledge, unique.

\section{Studies Included}

We reviewed 61 papers on the employment effects of minimum wages in developing countries - all of the papers we identified that met our study criteria. To select these papers, we searched on Google scholar for published journal papers as well as unpublished papers, covering all the regions in the developing world. ${ }^{6}$ We searched using keywords related to minimum wages and developing countries. Our search was conducted from April 2017 to August 2017. We also consulted recent surveys (Belman and Wolfson, 2016; Broecke et al., 2017) to check for any papers we missed, which resulted in adding two additional papers from Belman and Wolfson (2016). ${ }^{7}$ We focused mainly on recently published papers (published since 2000), because we wanted to analyze the burgeoning wave of minimum wage papers in developing countries; of the 61 in our survey, $93.4 \%$ were published after $2000 .{ }^{8}$ Most of the papers are in English, but we also include papers in Spanish and Portuguese. We also restricted the analysis to papers that report employment elasticities with respect to the minimum wage, or for which we had enough information to compute these elasticities. ${ }^{9}$

We created a data set of all estimates from these papers, as well as information on the statistical 
significance of the estimates. However, because many papers present estimates that the authors do not view as credible (e.g., showing the estimates for panel data specification without the fixed effects), we also tried to extract the authors' main or preferred estimates from each study. Specifically, we read each paper in detail and selected preferred estimates following three rules. First, in some cases the authors specifically say that a subset of estimates are their preferred results. This kind of statement is based, for example, on the authors presenting specifications missing some controls (e.g., year fixed effects), while arguing that the controls are needed to correctly estimate the effects of minimum wages. Second, in the absence of such an explicit statement, authors often summarize what they say are their main findings, underscoring some specific estimates by referring only to these estimates in the abstract, the introduction, or the conclusion. Third, absent either of these conditions, if estimates are reported for many regions in a country, we select the estimate for the whole country as the preferred result. In applying these rules for selecting preferred estimates, rule one overrode rules two and three, and rule two overrode rule three. Thus, for instance, if the authors point out that their preferred result is for region A, we use region A as the main result instead of the estimate of the whole country. However, in the spirit of a meta-analysis, we do not impose (or even offer) our subjective assessments of which studies are more credible, and do not discard studies or estimates that could plausibly be viewed as less credible or plausible. ${ }^{10}$

Finally, it is important to mention that studies sometimes report estimates for different groups or sectors, like all workers and more vulnerable workers, or the formal and the informal sector. We capture all of these estimates, but also flag - when the authors do - the subset of these estimates preferred by the authors, based on the rules above.

We believe that in analyzing the set of estimates from a research literature, it makes sense to focus on the preferred estimates. For example, suppose there are two papers estimating the effect of policy X, and both authors believe that one needs to instrument for policy $\mathrm{X}$ to get the causal effect. If one paper presents only the instrumental variables (IV) estimate, while the other presents both the OLS and the IV estimate, then why give weight to the OLS estimate in summarizing the evidence? Neither author believes the OLS effect is of interest, and the second author chose to include it for some other reason - perhaps to confirm 
the expected direction of the bias in the OLS estimate, for which the IV corrects. ${ }^{11}$ At the same time, we understand that the selection of preferred estimates potentially allows for an element of subjectivity compared to simply capturing all estimates in the surveyed papers; our use of a set of rules for identifying authors' preferred estimates is intended to mitigate any concerns regarding our decisions about which estimates to study.

Across the 61 studies, there are 1,250 total estimates. There are 15 studies that report the effects of the minimum wage on the probability of being employed (or something closely related), rather than an elasticity, but for which we could recover estimates of elasticities. We compute these elasticities using reported means of employment rates and the minimum wage if the paper reported them; if these were not reported, we used alternative data sources to obtain these averages and estimate the elasticities. The data sources and calculations for this subset of studies are described in Appendix Table A1. ${ }^{12}$

Table 1 reports descriptive information on the estimated minimum wage-employment elasticities in the studies we surveyed. Across all the estimates in the surveyed studies, the average estimated elasticity is -0.061 , the maximum elasticity is 4.51 , and the minimum is -4.73 . We identified 229 preferred estimates, using the rules discussed above. The average elasticity for this subset of estimates is -0.102 , with a maximum of 2.19 and a minimum of -2.53 . The standard deviation is 0.497 , very similar to the standard deviation for all estimates (0.451). Note that the authors' preferred estimates exclude some more extreme elasticity estimates.

Figure 1 provides histograms for the two sets of estimates, to provide more evidence on their distributions. We plot only estimates between -1 to 1 to make the figure easier to read. ${ }^{13}$ Panel A provides the histogram for the full set of estimates, and Panel B for the preferred estimates. The negative means and medians of the estimates are clear for both sets of estimates, as is the fact that there clearly are positive estimates. Note also that the medians are closer to zero.

\section{Classifying Studies/Estimates, and Predictions for Employment Effects}

The key question we assess is whether there are systematic differences across studies and estimates that explain the variation in estimated employment effects. In particular, we classify the estimates in the 
studies in our survey by specific features of the estimates. We then ask whether features of estimates more likely to predict negative effects either based on economic theory - specifically, the competitive model of the labor market - or because of institutional factors, in fact do so. As an example, the competitive model of the labor market would predict that less-skilled workers are more adversely affected by a higher minimum wage. We classify estimates based on four features. Appendix Table A2 lists the studies we use, the preferred estimates as discussed earlier, and the classification of studies and estimates - which we now discuss in detail.

\section{Binding minimum wages}

The first feature we use to classify estimates is whether minimum wages are binding. There are different ways to measure the bindingness of minimum wages. One measure sometimes used in the minimum wage literature is a projected fraction affected, an estimate of the fraction of workers earning below the minimum wage before an increment. However, only 12 of 61 papers that we reviewed report this measurement. Instead, we use as a proxy for bindingness evidence of a positive effect of the minimum wage on average wages - evidence that is reported much more commonly (in 44 of the 61 papers). A potential limitation of this "binding" measure is that the effect on wages depends on the employment response. But we are less concerned with the precise magnitude than with whether the study provides evidence that wages of employed workers are increased, and we do not think that anyone's reading of the minimum wage literature is that the employment response to a minimum wage is ever so strong that it would obscure evidence of a positive effect of the minimum wage on wages. Indeed, this is consistent with the evidence we report below; most studies that test for an effect on wages find such an effect, consistent with binding minimum wages.

If the study reported a statistically significant positive effect of the minimum wage on wages, or evidence of a spike in the wage distribution at the minimum wage (based on visual inspection of figures as described by the authors), we classify the corresponding employment estimate as pertaining to a binding minimum wage. If evidence was reported and does not indicate a positive effect on wages, we classify the study as pertaining to a non-binding minimum wage. Our third category is "no data," meaning that the 
study did not report evidence on effects on wages; this third category is retained in our analysis, rather than dropping these observations. ${ }^{14}$ We would expect more evidence of adverse effects of minimum wages on employment when minimum wages are binding, at least under the competitive model..$^{15}$

Sector

The second feature we use to classify estimates is whether the estimate was for the formal sector, the informal sector, or both (total employment). In the formal (also called "covered") sector, minimum wage laws apply, in principle at least. Minimum wage laws do not cover the informal sector. The informal sector can be defined by firms that operate illegally, by self-employed workers and, as in Chun and Khor (2010) and Del Carpio et al. (2015), by small firms that enforcement authorities do not visit. In developing countries, both sectors can be sizable. The distinction between the effects for the formal and informal sector in developing countries is important. A high share of jobs is estimated to be informal: $46.8 \%$ of jobs in Latin America (ILO, 2015a), 66\% in Sub-Saharan Africa (ILO, 2015b), and 68.2\% in Asia-Pacific (ILO, 2018).

Some papers do not report if their estimates cover the formal sector, the informal sector, or both sectors. However, we were able to classify these papers by analyzing the data used. For example, for Mexico there are two main employment surveys - the Employment and Occupation Survey, and Social Security Administrative Data. The former has data on both sectors; hence, if the author uses total employment from this survey, we know that the estimates cover both sectors. The latter survey only has data for formal-sector workers, and thus we know that estimates using this survey are for the formal sector. All the estimates could be classified along this dimension.

The prediction from the standard two-sector competitive labor market model is that a higher minimum wage reduces employment in the formal sector, because in the formal sector minimum laws (and other labor regulations) apply and are more likely to be enforced. However, employment in the informal sector may increase, depending on informal sector wages and the expected value of search for formalsector work while employed vs. not employed in the informal sector (Harris and Todaro, 1970; Mincer, 1976). However, some recent work has highlighted the potential for different effects in the informal sector. 
For example, Gindling (2018) argues that some evidence points to wage increases in the informal sector from "lighthouse effects" that may arise because employers have to compete for workers with the formal sector, leading to minimum wages constraining the wages employers pay in the informal sector and hence reducing employment there. ${ }^{16}$ Other studies, in contrast, have found no effect on wages in the informal sector (Papps, 2012; Carneiro and Corseuil, 2001). Thus, we should expect adverse employment effects of minimum wages in the formal sector - at least under the competitive model - whereas the prediction for the informal sector is perhaps less clear.

\section{Enforcement}

Our third feature of estimates is the degree of enforcement of the minimum wage law, which we break into three categories. Countries with no enforcement are those whose laws do not penalize violations of the minimum wage law. Countries with weak enforcement have low-cost fees for a violation. And countries with strong enforcement are those that specify severe penalties for not abiding by the law, like time in prison or shutdown of the company. The prediction, of course, is that minimum wages should have more impact generally, including reducing employment (according to the competitive model), when minimum laws are more strongly enforced. All the estimates are classified in one of these three categories.

The classification of enforcement is developed and described in Munguía Corella (2019). He systematizes labor codes and minimum wage laws by country, and constructs an indicator for the degree of enforcement, using the ILO’s “Database of National Labour, Social Security and Related Human Rights Legislation" (NALEX). ${ }^{17}$ NALEX compiles records of labor laws for 196 countries and 160 territories. As an illustrative example, Ghana does not have any penalty specified in its Labor Act of 2003; the Act established a Tripartite Committee that oversees the minimum wage rate, but does not specify what happens when an establishment fails to abide by the law. Hence, Ghana is classified as having "no enforcement." In contrast, in Bolivia fines are costly (up to 1,447 USD per violation), and the authorities can shut down an establishment in case of repeated violations. Hence Bolivia is classified as having "strong enforcement." Given the constraints of the data used to classify enforcement, the degree of enforcement is assigned at the country level and does not change over time. 
There are some potential challenges in the analysis classifying estimates based on enforcement.

First, the enforcement measure captures potential penalties. It is possible that in some countries, even if the law is stringent, actual implementation is weak, owing to weak institutions in the country, a lack of labor inspectors, or corruption among the enforcement authorities. However, in a more standard panel data analysis of the effects of minimum wages in developing countries, Munguía Corella (2019) finds stronger adverse employment effects when the law dictates stronger enforcement, without regard to how well labor laws are enforced (although also finding that enforcement has stronger effects in countries with more effective labor market regulations, based on a World Bank index). Thus, the enforcement variable should provide some information about a country's commitment to its minimum wage laws. Second, the enforcement of the minimum wage could be endogenous. For instance, if, in some countries, the minimum wage is destroying low-skill employment, workers (or policymakers) might adopt weak enforcement "on the ground," despite what the law says, to mitigate the adverse effects, making it difficult to estimate the exogenous effect of enforcement. ${ }^{18}$

Vulnerability/low-skill

Finally, the fourth feature of estimates we use in our classification is whether the estimate is for low-skilled or "vulnerable" workers, or instead for all workers. We classify studies or estimates for vulnerable workers as those estimated for young adults, for women, or for unskilled workers. The competitive model of labor markets, of course, predicts that we should find stronger evidence of adverse employment effects of minimum wages in data on vulnerable workers because their wage is more likely to directly affected by the minimum wage. However, if the minimum wage is very low, it is possible that it is not binding even for low-wage, vulnerable workers. All the estimates are classified as pertaining to either vulnerable workers or all workers.

\section{Differences in Estimated Employment Effects: Evidence}

We now turn to our analysis exploring how estimated employment effects vary with features of the estimates. In particular, we focus on whether the evidence is more consistent with negative employment effects for estimates based on one or multiple features that predict more adverse employment effects of 
minimum wages, and conversely whether there is less evidence of negative effects when these features are absent.

\section{Differences in estimates: one-way comparisons}

We begin, in Table 2, with univariate comparisons across estimates. Table 2 reports the number and percent of estimated employment elasticities with respect to the minimum wage that are negative and significant, insignificant, or positive and significant, for estimates with each of the four features by which we classify them: binding minimum wages, sector, enforcement, and type of workers; we classify estimates as significant based on a significance level of $5 \% .{ }^{19}$ This table is based on the authors' preferred estimates of the employment elasticity, summarized in the second row of Table 1 and in Panel B of Figure 1.

To better understand what is reported in Table 2, consider a specific example. Bhorat et al. (2014) analyze the effects on formal-sector wages and employment in South Africa. Their results indicate that the elasticity of wages with respect to the minimum wage is between 0.176 and 0.22 (statistically significant). Hence, these results are classified as "binding." For employment effects, they have two preferred elasticities (based on different econometric models); both are negative but only one is statistically significant. Hence, this study results in one negative and significant elasticity and one insignificant elasticity reported in the "Binding" row of Panel A in Table 2, and one negative and significant elasticity and one insignificant elasticity reported in the "Formal" row in Panel B. Because South Africa has weak penalties, this study is also coded as having one negative and significant elasticity and one insignificant elasticity in the "Weak" row in Panel C. And finally, these estimates cover all workers, rather than just vulnerable workers, and hence this study results in one negative and significant elasticity and one insignificant elasticity in the "All workers" row in Panel D. In the "Total" column, the rows in each panel add to the total number of estimates (229), because all the estimates are classified by each of the four features.

Panel A of Table 2 reports results based on whether the minimum wage is binding, non-binding, or there are no data on wages with which to classify the study and its estimates. There is somewhat more evidence of negative employment effects when minimum wages are binding (or are likely to be binding - 
as discussed below). For the estimates based on binding minimum wages, $38.2 \%$ of the elasticities (63 estimates) indicate negative and significant effects on employment. Only $6.7 \%$ of the results (11) with a binding minimum wage report positive and significant elasticities. In 55.2\% of the cases (91) the estimated employment elasticity is insignificant. Thus, for binding minimum wages, if the estimated elasticity is significant, the evidence points much more strongly to adverse employment effects than to positive employment effects, although the share of negative and significant employment elasticities is lower than the share of insignificant elasticities.

There is only a small number of estimated elasticities from studies where the minimum wage is non-binding (11), and nearly three-quarters of them (72.7\%) report an insignificant employment elasticity. However, the remainder (27.3\%) of the estimated employment elasticities are negative and significant.

There is a sizable number of studies with no information on whether the minimum wage is binding (53 estimated elasticities). Among these, the results are very similar to the estimates based on studies reporting that the minimum wage is binding, with $37.7 \%$ of the estimated employment elasticities negative and significant, and $43.4 \%$ insignificant. Given the distribution of estimates (and studies) as having binding or non-binding minimum wages in the first two rows - with nearly all indicating that minimum wages are binding - it seems likely that in most of the unclassifiable studies the estimated minimum wage effect is in fact for a binding minimum wage. For instance, as shown in Appendix Table A3, China has four studies classified as "no data," but it has four that are classified as binding, and only one classified as non-binding, so it seems plausible that the minimum wage is binding in the first four. Similarly, Brazil has three studies classified as "no data," 12 classified as binding, and none classified as non-binding. Thus, it seems reasonable to view the results in the "No data" row of Table 2 as largely reinforcing the conclusion that estimates of the effects of binding minimum wages point to disemployment effects, although to be more agnostic we continue to treat these two groups of studies separately, and to study binding minimum wages we focus on the estimates for which we can explicitly classify the data as pointing to a minimum wage that is binding.

Panel B reports results for estimates classified by sector - formal or informal. The results tend to 
point to evidence of negative employment elasticities in both sectors. However, there is more evidence of positive effects for estimates based on the informal sector, and a little more evidence of negative effects for the formal sector. For the formal-sector estimates, 38.4\% of the estimated elasticities (53 estimates) point to negative employment effects, while only $7.2 \%$ (10) point to positive employment effects; $54.3 \%$ of estimates (75) are insignificant. For the informal sector, the percentage of positive and significant employment elasticities is more than double that for the formal sector (18.8\% vs. $7.2 \%)$, although still, more estimates are negative or insignificant (33.3\% negative, and $47.9 \%$ insignificant). For estimates covering both sectors, the percentage of estimates that are negative and significant is similar, and the percentage of insignificant estimated elasticities is higher.

Panel C disaggregates the estimated elasticities based on enforcement. In this case, the results for strong vs. weak enforcement indicate more evidence of negative employment effects with strong enforcement, but the comparisons with no enforcement appear to be counterintuitive. In particular, the elasticities for minimum wage laws with strong enforcement are negative and significant in $46.0 \%$ of cases (29 estimates), compared to $29.6 \%$ (29) with weak enforcement; but the percentage is slightly higher $(46.8 \%)$ with no enforcement. Thus, there is not a clear pattern of a greater percentage of insignificant elasticities the weaker is enforcement. These results may reflect some of the challenges we discussed earlier with respect to measuring enforcement and assessing its "effect" on the estimated minimum wage effect.

Finally, Panel D turns to results disaggregated by type of worker. Estimates for vulnerable workers point more clearly to disemployment effects - with $45.7 \%$ of such estimates (37) negative and significant, compared to a lower percentage $(33.1 \%)$ for estimates computed instead for all workers. ${ }^{20}$ Correspondingly, there is a lower percentage of estimates with positive effects when looking at vulnerable workers compared to all workers $(7.4 \%$ vs. $10.1 \%)$, and the percentage with insignificant results is lower for vulnerable workers $(46.9 \%$ vs $56.8 \%)$.

Thus, based on the univariate comparisons, for three of the four classifications of estimates we use - binding minimum wages, sector, and type of worker - we find some evidence consistent with minimum 
wages doing more to reduce employment where there is a stronger prediction of negative employment effects, and for the formal/informal-sector distinction, more evidence of positive effects in the informal sector. These results are consistent with expectations from the competitive model (while not necessarily contradicting other models), including the two-sector model. We next turn to evidence that more sharply delineates studies and estimates by simultaneously considering multiple features of these estimates.

\section{Differences in estimates: multi-way comparisons}

The one-way comparisons we have presented thus far could mask relationships between study features and estimated elasticities, for four reasons. First, we may not be isolating the effect of a particular features of an estimate, because estimates can vary along multiple dimensions at once. Second, given that each of the features we study - bindingness, formality, enforcement, and vulnerability - can matter independently for whether minimum wages reduce employment, it follows that estimated employment effects may be more negative if more features of an estimate predict negative effects - based on the competitive model or institutional factors (and more so if they interact). Third, we have taken no account of the estimated magnitudes of the elasticities. And fourth, related to the last point, the signs of insignificant estimates are also of interest. ${ }^{21}$ Hence, we now present analyses that incorporate all of this information. For these analyses, we present evidence in sets of figures, rather than tables, because the figures make the evidence much clearer. In the next subsection, we turn to some regression estimates that refine the analysis further.

We begin with two-way comparisons based on pairs of features that more strongly predict negative employment effects based on the competitive model and institutional factors - for example, estimates covering vulnerable workers with strong enforcement, or estimates for the formal sector where minimum wages are binding. These are reported in Panel A of Figure 2A. Note that the third and fourth features are not specified (similar to in our one-way comparisons in Table 2), so two features predicting stronger negative effects means two or more features. Thus, for example, when we summarize the estimates for vulnerable workers with strong enforcement, we do not specify formal vs. informal sector or whether the minimum wage is binding. We report (as we do in the remaining panels of Figure 2A) the percentage of 
estimates that are positive but insignificant ("insignificant positive"), negative but insignificant (“insignificant negative"), positive and significant ("positive"), and negative and significant ("negative").

In Panel B, we report these percentages for estimated elasticities for which only one feature of the estimates in each possible pair of features predicts negative employment effects. Thus, for example, corresponding to the vulnerable/strong estimates in Panel A, we have two sets of estimates in Panel B vulnerable/none (no enforcement) and vulnerable/weak. We thus learn how removing the strong enforcement feature from the vulnerable/strong pair affects the estimates. And Panel $\mathrm{C}$ does this for pairs in which neither feature in the pair predicts negative employment effects. Corresponding to what we said above, in Panel B one or more features more strongly predict negative employment effects, and in Panel C at most two features more strongly predict negative employment effects (or alternatively two or more features do not predict more negative effects). Appendix Table A4 reports the total number of estimates for each pair shown in the figure and reports similar information for the figures that follow.

Figure 2A shows a few things. Looking first at Panel A, when two (or more) features of an estimate more strongly predict negative effects, the estimated elasticity is much more likely to be negative. This is reflected in the black bars (for negative effects) being, in all cases, much longer than the gray bars, indicating higher percentages of estimated elasticities that are negative. In all cases but one, fewer than $20 \%$ of estimates are positive - summing across the solid gray bars for negative and significant elasticities, and the patterned gray bars for negative and insignificant elasticities. This contrasts with Panels B and C when only one, or neither, feature in the pair considered predicts stronger negative effects. In Panel B, the differences between the black and gray bars - corresponding, respectively, to negative estimates and positive estimates - are less pronounced, and in some cases there are not many fewer positive than negative estimates (whether significant or not). ${ }^{22}$ This weaker evidence of negative effects when fewer features more strongly predict negative employment effects is even more apparent in Panel C, for which neither feature in the pair predicts stronger negative employment effects (meaning that at least two of the four features we consider do not more strongly reflect negative employment effects). Indeed, while Panel B still indicates a preponderance of negative elasticities, in Panel $\mathrm{C}$ there are multiple cases with a larger share of estimates 
that are positive (e.g., weak/no data (binding) and informal/all workers).

One might also ask, from this figure, if there is evidence about which features of estimates are more strongly associated with finding a negative employment effect. However, because the other features of estimates not in each pair considered can vary, this can be misleading. We come back to more explicit evidence on this question below.

Figure $2 \mathrm{~B}$ presents three panels for the same pairs of features, but this time reporting the average magnitude of the elasticity. In Panel A, for pairs in which both features of estimates more strongly predict negative employment effects, the elasticities are negative in every case, with one in the range of -0.06 range, four in the range of about -0.12 to -0.15 , and one around -0.20 . In Panel $\mathrm{B}$, the average elasticity is negative in all cases but one (strong/informal). But in many cases the elasticities are closer to zero (and some quite close), although there are some cases with larger negative elasticities. (However, the most extreme case, for "vulnerable/non-binding," is based on only two estimates.) Finally, in Panel C, when neither feature predicts stronger negative employment effects, there are more positive elasticities.

Thus, the evidence from Figures $2 \mathrm{~A}$ and $2 \mathrm{~B}$ suggests that when more features of estimated elasticities more strongly predict negative employment effects, the estimates are more likely to be negative. However, when we look at only pairs of features of estimates, the information can be quite noisy because the other two features of estimates not included in the pair are not specified. Hence, we next look at sharper evidence - based on whether at least three features of estimated elasticities, or all four features, more strongly predict negative employment effects based on the competitive model and institutional factors. This evidence paints an even clearer picture: when many features of an estimate more strongly predict negative employment effects, the evidence points quite unambiguously in that direction. In contrast, when many features do not more strongly predict negative employment effects, the evidence is much more mixed.

Figure $3 \mathrm{~A}$ presents the evidence on the sign and significance of the estimates, for estimates for which three or more features more strongly predict negative employment effect. In Panel A, the first set of bars (above the horizontal dashed line) are for all four features. For these estimates, all of the estimates are negative, with $57.1 \%$ significant and $36.7 \%$ insignificant. The remaining sets of bars are for estimates for 
each set of three features that more strongly predict negative employment effects. ${ }^{23}$ It is clear that for these estimates, nearly all of the estimates are negative, and more are statistically significant than not.

Panel B goes in the opposite direction, summarizing results for sets of features - in threes or all four - that do not more strongly predict negative employment effects. In this case, for which most (or none) of the features more strongly predict negative effects, there is no clear pattern of more negative than positive elasticities, and there are many sets of features for which there are more positive than negative effects (e.g., informal/weak/all workers and informal/weak/no data (binding). Note that for the bars above the dashed line, for estimates for which none of the four features more strongly predict negative effects, there are very few elasticities (see Appendix Table A4); hence the percentages reported for this set of bars, including the couple of cases of $100 \%$ negative elasticities, are not very reliable.

Figure 3B presents similar evidence, but for the magnitudes (average elasticities). Not surprisingly, the estimated magnitudes are all negative in Panel A, for estimates for which all or most features more strongly predict negative employment effects. In contrast, the evidence in Panel B, for estimates for which most features do not more strongly predict negative employment effects, is very mixed, with one-third of the sets of estimates on average positive. Note that all of the larger positive magnitudes (and six of the seven positive ones overall) correspond to estimates for the informal sector.

Overall, we view the evidence in Figures 3A and 3B as providing a quite clear message: When studies of the employment effects of minimum wages in developing countries have many (or most) features that more strongly predict negative employment effects, based on the competitive model and institutional factors, the evidence is a good deal more likely to point to negative employment effects.

\section{Differences in results across features of estimates: meta-regressions}

Finally, we turn to regression analysis of the estimates - or meta-regressions. We estimate models with three different dependent variables: a dummy variable for whether the estimate is negative; a dummy variable for whether it is negative and significant; and the estimated elasticity. For the first two cases, we use a linear probability model. We begin with simple specifications in which the regressors are mutually exclusive variables for whether zero, one, two, three, or four features of the estimates more strongly predict 
negative employment effects based on the competitive model or institutional factors. That is, for each of our outcomes, we estimate regression models of the form:

$$
Y_{j}=\beta_{0} S F_{j}^{0}+\beta_{1} S F_{j}^{l}+\beta_{2} S F_{j}^{2}+\beta_{3} S F_{j}^{3}+\beta_{4} S F_{j}^{4}+\varepsilon_{j},
$$

where there is no constant, $j$ indexes estimates, the $S F^{\#}$ are dummy variables for the number of estimate features predicting stronger negative employment effects, and the $Y_{j}$ are the alternative dependent variables. $S F_{j}^{0}$ is equal to one if none of the features of the estimates is classified as a stronger predictor of negative effects of the minimum wage on employment - a study that estimates the impact for the informal sector, on total employment (instead of vulnerable workers), for a country with weak enforcement, where the minimum wage is not binding. $S F_{j}^{l}$ is equal to one if the estimate is classified to have one feature that predicts stronger negative employment effects, and the other three do not. $S F_{j}^{2}$ is a dummy equal to one when two features predict negative employment effects, and so on.

This analysis provides some advantages relative to the preceding figures in terms of summarizing the evidence, at the cost of losing some of the richness of those figures. The regression estimates average over the sets of features of estimates we considered in the figures, which can increase precision but mask heterogeneous effects of study features. We are also able to do statistical inference on the results. And the regression analysis avoids the ambiguity of the whether the unspecified features of the estimates in the sets of two or three features of estimates considered in the figures do or do not more strongly predict negative employment effects - because the dummy variables $S F^{\#}$ are defined to be mutually exclusive. This metaregression differs from a regression using dummies for each category - one dummy for binding, one for formal sector, etc. We prefer this more restrictive specification because there are very few observations for some combinations of features (see Table A4 in the Appendix), although we describe richer specifications below.

The estimates of equation (1) are reported in Table $3 .{ }^{24}$ The sample includes all 229 preferred estimates from the 61 studies, and we cluster the standard errors by study. In general, we see more systematic evidence of the conclusions we drew from the figures: when more features of estimates more strongly predict negative employment effects, the estimates are more consistent with negative employment 
effects. The estimates in column (1) are for the dichotomous outcome of whether the estimated elasticity is negative. There is a positive monotonic relationship between the number of features of estimates that more strongly predict negative employment effects and the probability that the estimated elasticity is negative. (Indeed for four such features, there is no variation, as we saw in the top set of bars in Figure 3A.)

We see very similar evidence in column (2) - where the outcome is a negative and significant elasticity. There is just one deviation from monotonicity, for the difference between zero and one feature of estimates. The estimated coefficients are smaller than in column (1), implying that there is a stronger relationship between the number of features of estimates that more strongly predict negative employment effects and finding a negative employment effect without regard to significance, than finding a negative and significant one.

Finally, in column (3), for the actual estimated elasticities, the evidence is not quite as clean with regard to a monotonic relationship, reflecting the variability in the estimates. (Here the signs are flipped because the dependent variable is the elasticity, not a dummy for whether the elasticity is negative.) Moreover, the average estimated elasticity is significant only for cases where two features of estimates more strongly predict a negative employment effect, although the point estimate is larger when all four features of estimates more strongly predict a negative employment effect $(-0.192$ vs. -0.125$)$. As reflected in the counts of estimates with different numbers of features more strongly predicting negative employment effects (Appendix Table A4), this difference in statistical significance likely reflects at least in part the small number of estimates for which all four features more strongly predict negative employment effects.

Note that Table 3 also reports the statistical significance of the estimated differences based on the number of features that more strongly predict negative employment effects. For example, under the "Two estimate features" heading, the row labeled "Two = One (p-value)" is the p-value for the test of equality of the estimated coefficients of "Two estimate features" and "One estimate feature," or $\beta_{2}$ and $\beta_{1}$ in equation (2). Despite the generally quite clear relationships indicating that when there are more such features estimated employment effects are more likely to be negative, these differences often are not significant. They are, however, in a number of cases in columns (1) and (2), for tests of the difference in coefficients 
when all four features of estimates more strongly predict negative employment effects, vs. fewer features.

Next, we modify this framework to test more explicitly which features of estimates are more likely to lead to evidence of negative employment effects, or a larger negative elasticity. For the variables corresponding to one, two, or three features of estimates (from equation (1)) we alternatively define these to include or to exclude each estimate feature. For example, to ask whether evidence that the minimum wage is binding leads to stronger evidence of negative employment effects, we break each of the variables $S F_{j}{ }^{1}, S F_{j}^{2}$, and $S F_{j}^{3}$ into two separate variables, based on whether or not the estimate is for a binding minimum wage. In this example, denoting these, for $S F_{j}{ }^{l}$, as $S F_{j}{ }^{l B}$ and $S F_{j}{ }^{I N B}$, equation (1) becomes:

$$
\begin{aligned}
Y_{j}= & \beta_{0} S F_{j}{ }^{0}+\beta_{1}{ }^{B} S F_{j}{ }^{l B}+\beta_{1}{ }^{N B} S F_{j}{ }^{I N B}+\beta_{2}{ }^{B} S F_{j}^{2 B}+\beta_{2}{ }^{N B} S F_{j}{ }^{2 N B}+\beta_{3}{ }^{B} S F_{j}{ }^{3 B}+\beta_{3}{ }^{3 N B} S F_{j}{ }^{I N B} \\
& +\beta_{4} S F_{j}{ }^{4}+\varepsilon_{j} .
\end{aligned}
$$

Note that the variables corresponding to zero features or four features are unaffected by this change, because they cannot be broken up this way. For this specification, evidence of more negative estimates for $S F_{j}{ }^{l B}$ than for $S F_{j}{ }^{I N B}$ (or similarly for $S F_{j}^{2 B}$ vs. $S F_{j}^{2 N B}$ or $S F_{j}^{3 B}$ vs. $S F_{j}^{3 N B}$ ) would indicate that estimates for binding minimum wages - for the same number of estimate features more strongly predicting negative employment effects - are more likely to find evidence of negative employment effects. Hence, we also report tests of equality for these pairs of coefficients, for each study feature considered separately.

We report these results in Table 4, for the same outcomes as in Table 3 - a negative elasticity, a negative and significant elasticity, and the estimated elasticity itself. Each set of three columns considers one of our four features of estimates, with the variables for one, two, and three study features broken into separate dummy variables for whether or not that specific feature is included. The simplest way to interpret this evidence is to compare the estimated coefficients between the "includes feature" row and the "excludes feature" row, for a given number of features of estimated elasticities that more strongly predict negative employment effects.

Consider first the estimates in columns (1)-(3), for binding minimum wages. Column (1) reports results for whether the estimate is negative, comparing estimates that do and do not come from binding minimum wages. For estimates for which two features more strongly predict negative minimum wage 
effects, the estimated coefficient is larger in the "excludes feature" rows $(0.724$ vs. 0.711$)$ - i.e., when the two estimate features that more strongly predict negative employment effects do not include binding minimum wages. In contrast, for estimates for which three features more strongly predict negative employment effects, the coefficient is larger when one of these features is binding minimum wages $(0.824$ vs. 0.750). In column (2) as well - where the outcome is a negative and significant employment effect, the relative magnitudes of these coefficients do not exhibit a consistent pattern. However, in column (3) - for the actual magnitude of the elasticity - the average elasticity is always larger negative for the features of estimates that exclude binding minimum wages. The table also reports the p-values for the tests of equality of these pairs of coefficients. There is never significant evidence of differences in columns (1)-(3); the lowest p-value if 0.24 (for three features of estimates, in column (3)).

Columns (4)-(6) report the same kind of evidence, but this time distinguishing estimates by whether they are for the formal sector or not. In this case, too, the evidence for whether the estimated coefficient is negative or negative and significant is not unambiguously in one direction. However, in column (6) the estimated elasticity is always larger negative when formality is excluded. Again, none of these pairwise differences in estimates are statistically significant (except in one case in column (4), for an estimated coefficient that has no variation).

The estimates in columns (7)-(9) consider differences depending on whether the estimate features include or exclude strong enforcement. In this case, there is no clear difference. Finally, the estimates in columns (10)-(12) focus on whether the estimate is for vulnerable workers. In this case, again, there is not clear evidence that the evidence of negative employment effects, or the magnitude of the negative effect, differs systematically based on whether one of the estimate features is a focus on vulnerable workers. ${ }^{25}$

Note that the specification in Table 4 is different from what might be viewed as the most standard type of meta-regression that simply includes, on the right-hand side, dummy variables for the different study features. A regression like that would take no account of whether (for example) studies with binding minimum wages tend to have only one study feature that more strongly predicts negative employment effects, while studies focusing on the formal sector tend to have more features that more strongly predict 
negative employment effects. If studies are unlikely to detect negative employment effects unless multiple features of the study more strongly predict negative employment effects, then there are important interactions between specific study features and the number of features that more strongly predict negative employment effects, which the specifications in Table 4 could reveal.

Nonetheless, we have estimated versions of the more standard meta-regression, and report the results in Table 5. In the first three columns, we omit the weakest study feature in terms of predicting negative employment effects (non-binding, no enforcement, informal sector, and all workers). In the next three columns we use a more parsimonious model, retaining only the strongest such study feature (binding, strong enforcement, formal sector, and vulnerable workers) ${ }^{26}$ In this table, the clearest evidence is that studies focusing on vulnerable workers are most likely to provide evidence of negative employment effects, and there is also some evidence of this (although a good deal weaker) for studies of countries with strong enforcement. However, Table 4, which compares results based on study features for studies including the same number of features that more strongly predict negative employment effects, suggests we have to be a bit cautious about this interpretation. In Table 4, we find stronger evidence of negative effects for estimates with two features that more strongly predict negative employment effects when the estimates are for vulnerable workers, in all three columns ((10)-(12)); the p-values for equal effects are fairly small, although only one, in column (11), is below 0.1. But for estimates with other numbers of features that more strongly predict negative employment effects, the estimated effects are larger when the vulnerable worker feature is excluded. ${ }^{27}$

To summarize, Tables 3, 4, and 5 consider three different but related kinds of evidence. Table 3 focuses simply on the number of features of estimates - of the four we consider - that more strongly predict negative employment effects based on the competitive model or institutional factors. Table 4 tries to disaggregate this evidence, paying attention not only to the counts of estimate features, but also asking whether particular features of estimates among these four features are more consistently associated with evidence of negative employment effects, conditional on the number of features that more strongly predict negative employment effects. And Table 5 presents a more standard type of meta-regression that focuses on 
study features but without reference to how many other study features more strongly predict negative employment effects. In general, we do not find strong evidence pointing to particular features of estimates that generate stronger evidence of negative employment effects. There is some evidence of this for studies focusing on vulnerable workers, in Table 5, but this is not robust in Table 4. However, the evidence (from Table 3) is quite clear that estimated employment elasticities based on a greater number of features that more strongly predict negative employment effects are, in fact, more likely to be negative, or negative and significant. And such estimates, to a limited but lesser extent, are more likely to take on larger negative values.

One potential caveat to our interpretation of the evidence is that it is conceivable that the study features noted or documented by a study's authors were chosen (or emphasized) to rationalize a particular result. ${ }^{28}$ For example, a researcher failing to find a negative employment effect might be compelled to study whether the minimum wage was in fact binding, and provide evidence that is was not, whereas a researcher finding (and expecting) a negative employment effect might not. Or a researcher might first estimate employment effects for all workers, but after not finding a negative employment effect decide to look at more vulnerable workers, leading to finding a negative effect. In these examples, researchers who believe in the competitive model could end up highlighting features of the data, country, etc., which help rationalize the results in terms of the competitive model - what we might term "analysis bias" as opposed to "publication bias." We cannot decisively rule this out, although our sense is that the problem is not likely to be severe. First, some of our study features are beyond the researcher's control (like enforcement, or whether the data break out formal- and informal-sector workers). Second, for the analyses that reflect research decisions about what to explore (whether the minimum wage is binding, estimating effects for the formal and informal sector, and isolating effects for vulnerable workers), we would argue that these issues are very standard in the research literature on minimum wages in developing countries, suggesting most researchers would present these analyses as long as the data are available. ${ }^{29}$

\section{Conclusions}

The goal of this paper is to see whether we can make sense of the mixed evidence on the 
employment effects of minimum wages in developing countries. Although estimated effects tend to be negative, there is considerable heterogeneity, with many non-negative estimates. We try to distinguish between two explanations. One is that there simply is no clear evidence that minimum wages reduce employment in developing countries, in which case we should see heterogeneous estimates even across similar studies or estimates looking at workers most likely to be adversely affected by minimum wages (because, e.g., they are low skill, or work in the formal sector), and in contexts where negative effects are more likely (e.g., when minimum wages are more binding). Alternatively, the heterogeneity in estimated minimum wage effects may reflect heterogeneity in estimates along dimensions more likely or less likely to predict negative employment effects - e.g., estimates for binding minimum wages for low-skill workers vs. estimates for weakly enforced minimum wages in the informal sector, and estimates for which more features more strongly predict negative employment effects. To try to distinguish between these explanations, we conduct different versions of meta-analyses of the estimates from a large set of studies of minimum wage effects in developing countries.

We conclude that the evidence is much more consistent with the second explanation. That is, we find that the estimated employment effects of minimum wages in developing countries are more likely to be negative, and larger negative, when estimates focus on data and sectors for which the competitive model predicts disemployment effects and in institutional settings in which we would expect the minimum wage to have more adverse impact. Specifically, there is more consistent evidence of negative employment effects for estimates for which multiple features of the estimates - including when the minimum wage is binding, where minimum wage enforcement is stronger, for the formal sector, and when the data focus on vulnerable (lower-wage) workers - predict negative employment effects. To be precise, the evidence is less clear on whether a particular one of these features that characterizes a study is more strongly associated with negative employment effects (although there some evidence that disemployment effects are more likely to emerge from studies of vulnerable - i.e., lower-wage workers). The difficulty of pinning down exactly which study features matter the most for whether the evidence points to negative employment effects likely arises because studies can vary on many 
dimensions (corresponding to all of these features). But the evidence is clearer that when all or most features of a study predict negative employment effects, the study is in fact more likely to find negative employment effects.

One implication of this conclusion is that the apparently mixed evidence is a result of many studies focusing on data, sectors, or institutional settings in which negative employment effects are less likely. As such, many of these studies may be uninformative about the effects of minimum wages when the competitive model and institutional factors more strongly predict negative employment effects: studies of binding minimum wages, with strong enforcement, focusing on vulnerable workers, in the formal sector. On the other hand, the implication is that in some developing country settings negative employment are in fact less likely - e.g., for informal sector employment. However, a further implication is that precisely when minimum wages in developing countries could potentially deliver the most benefits - when minimum wages are binding and enforced, and when they apply to vulnerable workers in the formal sector - the disemployment effects are most apparent, implying that minimum wages in developing countries may present more of a tradeoff between higher wages and lower employment than might be apparent from a simpler look at the evidence across studies of employment effects in developing countries. Hence, in assessing the wisdom of minimum wage increases in developing countries, it is important also to weigh evidence on other outcomes, such as whether higher minimum wages in developing countries raise incomes of low-income families - benefits that might offset the costs of some job losses for vulnerable workers. Gindling (2018) suggests that, overall, minimum wages tend to reduce poverty in developing countries, but only modestly. ${ }^{30}$

Finally, one dimension we do not explore is whether monopsony power is sometimes relevant. There are some cases of positive estimates (although not many) with features for which the competitive model and institutional factors predict negative employment effects. (These positive estimates are more prevalent in studies with only one feature for which the competitive model and institutional factors predict negative effects; see, e.g., Figures 2A and 3A). Monopsony is a potential explanation, but not the only one; for example, the standard two-sector competitive model predicts positive employment effects in 
the informal sector. Testing whether monopsony can sometimes explain a positive effect of the minimum wage on employment is hard. Recent work for the United States (Azar et al., 2019; Munguía Corella, forthcoming) tries to do this using disaggregated, sub-national variation in measures of labor market concentration and worker mobility, and finds some evidence consistent with monopsony power in morerural, less-dense counties. There is no way to apply this type of analysis to the "study-level" or "estimatelevel" observations we use in the present paper, but exploring whether monopsony power sometimes generates positive employment effects of the minimum wage in developing countries would be useful.

Still, at this point our view is that there is no clear reason, based on the existing evidence, to conclude that competitive models of the labor market do not do a good job of characterizing low-wage labor markets in developing countries. Evidence of negative employment effects tends to emerge where the competitive model predicts it should, although this conclusion does not apply to every study, and different conclusions more consistent with monopsony could hold for some countries or more likely subregions of countries. 


\section{References}

Alaniz, E., Gindling, T., \& Terrell, K. (2011). The impact of minimum wages on wages, work and poverty in Nicaragua. IZA Discussion Paper No. 5702.

Alatas, V., \& Cameron, L.A. (2008). The impact of minimum wages on employment in a low-income country: A quasi-natural experiment in Indonesia. ILR Review, 61(2), 201-223.

Arango, C., \& Pachón, A. (2004). The minimum wage in Colombia: Holding the middle with a bite on the poor. Banco de la República Borradores de Economía Working Paper No. 280.

Asmal, Z., Bhorat, H., Kanbur, R., Ranzani, M., \& Paci, P. (2019). Minimum wages and labor supply in an emerging market: The case of Mauritius. Development Policy Research Unit Working Paper 201809. DPRU, University of Cape Town.

Azar, J., Huet-Vaughn, E., Marinescu, I., Taska, B., \& von Wachter, T. (2019). Minimum wage employment effects and labor market concentration. NBER Working Paper No. 26101.

Baranowska-Rataj, A., \& Magda, I. (2015). The impact of the minimum wage on job separations and working hours among young people in Poland. Institute of Statistics and Demography, Warsaw School of Economics Working Paper No. 45.

Bell, L. (1997). The impact of minimum wages in Mexico and Colombia. Journal of Labor Economics, 15(3), S102-S135.

Belman, D., \& Wolfson, P.J. (2019). 15 years of research on U.S. employment and the minimum wage. LABOUR, 33(4), 488-506.

Belman, D., \& Wolfson, P.J. (2016). What does the minimum wage do in developing countries? A review of studies and methodologies. International Labor Office, Conditions of Work and Employment Series 62.

Bhorat, H., Kanbur, R., \& Stanwix, B. (2014). Estimating the impact of minimum wages on employment, wages and non-wage benefits: The case of agriculture in South Africa. American Journal of Agricultural Economics, 96(5), 1402-1419.

Boeri, T., Garibaldi, P., \& Ribero, M. (2011). The lighthouse effect and beyond. Review of Income and 
Wealth, 57(special issue), S54-S78.

Broecke, S., \& Vandeweyer, M. (2015). Doubling the minimum wage and its effect on employment: Evidence from Brazil. http://conference.iza.org/conference_files/worldb2015/broecke_s8754.pdf.

Broecke, S., Forti, A., \& Vandeweyer, M. (2017). The effect of minimum wages on employment in emerging economies: A survey and meta-analysis. Oxford Development Studies, 45(3), 366-391.

Card, D., \& Krueger, A. (1995). Time-series minimum-wage studies: A meta-analysis. American Economic Review, 85(2), 238-243.

Carneiro, F. (2004). Are minimum wages to blame for informality in the labour market? Empirica, 31(4), 295-306.

Carneiro, F., \& Corseuil, C. (2001). Os impactos do salário mínimo sobre emprego e salários no Brasil: Evidências a partir de dados longitudinais e séries temporais. Instituto de Pesquisa Econômic Aplicada Discussion Paper No. 0849.

Castillo-Freeman, A., \& Freeman, R.B. (1992). When the minimum wage really bites: The Effect of the US-level minimum on Puerto Rico. In G. Borjas and R. Freeman (Eds.), Immigration and the work force: Economic consequences for the United States and source areas (pp. 177-211). Chicago: University of Chicago Press,.

Chun, N., \& Khor, N. (2010). Minimum wages and changing wage inequality in Indonesia. Asian Development Bank Economics Working Paper Series No. 196.

Clemens, J., \& Strain, M.R. (2020). Understanding "wage theft": Evasion and avoidance responses to minimum wage increases. NBER Working Paper No. 26969.

Comola, M., \& Mello, L. (2011). How does decentralized minimum wage setting affect employment and informality? The case of Indonesia. Review of Income and Wealth Series, 57(s1), S79-S99.

Cunningham, W. (2007). Minimum wages and social policy: Lessons from developing countries. The World Bank.

http://documents.worldbank.org/curated/en/826061468142780021/pdf/405260Minimum0101OFFICIA LOUSE0ONLY1.pdf. 
Del Carpio, X., Nguyen, H., Pabon, L., \& Wang, L.C. (2015). Do minimum wages affect employment? Evidence from the manufacturing sector in Indonesia. IZA Journal of Labor \& Development 4:17 (online).

Del Carpio, X., Messina, J., \& Sanz-de-Galdeano, A. (2014). Minimum wage: Does it improve welfare in Thailand? IZA Discussion Paper No. 7911.

Dinkelman, T., \& Ranchhod, V. (2012). Evidence on the impact of minimum wage laws in an informal sector: Domestic workers in South Africa. Journal of Development Economics, 99(1), 27-45.

Doucouliagos, H., \& Stanley, T.D. (2009). Publication selection bias in minimum-wage research? A metaregression analysis. British Journal of Industrial Relations, 47(2), 406-428.

Dung, P.K. (2017). The effects of minimum wage hikes on employment and wages in Viet Nam's micro, small, and medium enterprises. United Nations University WIDER Working Paper No. 2017/95.

Fajnzylber, P. (2001). Minimum wage effects throughout the wage distribution: Evidence from Brazil's formal and informal sectors. CEDEPLAR Working Paper No. 151.

Fang, T., \& Lin, C. (2015). Minimum wages and employment in China. IZA Journal of Labor Policy 4:22 (on-line).

Feliciano, Z.M. (1998). Does the minimum wage affect employment in Mexico? Eastern Economic Journal, 24(2), 165-180.

Foguel, M. (1998). Uma avaliação dos efeitos do salário mínimo sobre o mercado de trabalho no Brasil. Discussion Paper No. 564.

Foguel, M., Ramos, L., \& Carneiro, F. (2001). The impacts of the minimum wage on the labor market, poverty and fiscal budget in Brazil. IPEA Working Paper No. 839.

Franco, A., Malhotra, N., \& Simonvits, G. (2014). Publication bias in the social sciences: Unlocking the file drawer. Science, 345(6203), 1502-1505.

Garza Cantú, V., \& Cantú Bazaldúa, F. (2002). La dinámica macroeconómica de los salarios mínimos en el empleo de México: Un análisis empírico 1983-2000. In Comisión Nacional de los Salarios Mínimos (Ed.), Comisión consultiva para la modernización del sistema de los salario mínimos: Estudios y 
ponencias (pp. 299-368). Mexico: STPS.

Gindling, T.H. (2018). Does increasing the minimum wage reduce poverty in developing countries. IZA World of Labor 30.v2 (on-line).

Gindling, T., \& Terrell, K. (2007). The effects of multiple minimum wages throughout the labor market. Labour Economics, 14(3), 485-511.

Gindling, T., \& Terrell, K. (2009). Minimum wages, wages and employment in various sectors in Honduras. Labour Economics, 16(3), 291-303

Grau, N., \& Landerretche, O. (2011). The labor impact of minimum wages: A method for estimating the effect in emerging economies using Chilean panel data. University of Chile, Department of Economics, Working Paper No. 329.

Ham, A. (2018). The consequences of legal minimum wages in Honduras. World Development, 102(C), $135-157$.

Harris, J.R., \& Todaro, M.P. (1970). Migration, unemployment and development: A two-sector analysis. American Economic Review, 60(1), 126-142.

Harrison, A., \& Scorse, J. (2010). Multinationals and anti-sweatshop activism. American Economic Review, 100(1), 247-273.

Hernandez Diaz, G., \& Pinzon Garcia, E. (2006). El efecto del salario mínimo sobre el empleo y los ingresos. Departamento Nacional de Planeación, Archivos de Economía No. 316.

Hernandez, G., \& Lasso, F. (2003). Estimación de la relación entre salario mínimo y empleo en Colombia: 1984-2000. Revista de Economía del Rosario, 6(2), 117-138.

Hertz, T. (2005). The effect of minimum wages on the employment and earnings of South Africa's domestic service workers. Development Policy Research Unit Working Paper No. 05(99).

Hohberg, M., \& Lay, J. (2015). The impact of minimum wages on informal and formal labor market outcomes: Evidence from Indonesia. IZA Journal of Labor \& Development 4:14 (on-line).

Huang, Y., Loungani, L., \& Wang, G. (2014). Minimum wage and firm employment: Evidence from China. IMF Working Paper No. 14-184. 
Hunt, M. 1997. How science takes stock: The story of meta-analysis. New York: Russell Sage Foundation. International Labour Organization (ILO). (2015a). Transition to the formal economy in Latin America and the Caribbean. https://www.ilo.org/wcmsp5/groups/public/---americas/---rolima/documents/genericdocument/wcms_490793.pdf.

International Labour Organization (ILO). (2015b). Five facts about informal economy in Africa. https://www.ilo.org/africa/whats-new/WCMS_377286/lang--en/index.htm.

International Labour Organization (ILO). (2018). More than 68 per cent of the employed population in Asia-Pacific are in the informal economy. https://www.ilo.org/asia/mediacentre/news/WCMS_627585/lang--en/index.htm.

Islam, I., \& Nazara, S. (2000). Minimum wage and the welfare of Indonesian workers. International Labour Organization, Occasional Discussion Paper Series No. 3.

Kamińska, A., \& Lewandowski, P. (2015). The effects of minimum wage on a labour market with high temporary employment. IBS Working Paper No. 07/2015.

Lemos, S. (2004a). Minimum wage policy and employment effects: Evidence from Brazil. Economía, 5(1), 219-266.

Lemos, S. (2004b). A menu of minimum wage variables for evaluating wages and employment effects: Evidence from Brazil. IZA Discussion Paper No. 1069.

Lemos, S. (2004c). The effects of the minimum wage in the formal and informal sectors in Brazil. IZA Discussion Paper No. 1089.

Lemos, S. (2005a). Political variables as instruments for the minimum wage. Contributions to Economic Analysis \& Policy 4:1 (on-line).

Lemos, S. (2005b). Minimum wage effects on wages, employment and prices: Implications for poverty alleviation in Brazil. Division of Economics, School of Business, University of Leicester Working Paper No. 05(15).

Lemos, S. (2007). Minimum wage effects across the private and public sectors in Brazil. The Journal of Development Studies, 43(4), 700-720. 
Lemos, S. (2009a). Minimum wage effects in a developing country. Labour Economics, 16(2), 224-237.

Lemos, S. (2009b). Comparing employment estimates using different minimum wage variables: The case of Brazil. International Review of Applied Economics, 23(4), pp. 405-25.

Luo, R., Zhou, M., \& Wu, W. (2011). Impacts of minimum wage on employment of migrant workers in China. In Q. Zhou (Ed.), Advances in applied economics, business and development (pp. 73-77). Berlin-Heidelberg: Springer.

Magruder, J. (2013). Can minimum wages cause a big push? Evidence from Indonesia. Journal of Development Economics, 100(1), 48-62.

Majchrowska, A., \& Zółkiewski, Z. (2012). The impact of minimum wage on employment in Poland. Investigaciones Regionales, 24, 211-239.

Maloney, W., \& Nuñez Mendez, J. (2004). Measuring the impact of minimum wages: Evidence from Latin America. In J. J. Heckman and C. Pagés (Eds.), Law and employment: Lessons from Latin American and the Caribbean (pp. 109-130). Chicago: University of Chicago Press.

Martinez, C., Morales, G., \& Valdes, R. (2001). Cambios estructurales en la demanda por trabajo en Chile. Economía Chilena, 4(2), 5-25.

Mayneris, F., Poncet, S., \& Zhang, T. (2014). The cleansing effect of minimum wage: Minimum wage rules, firm dynamics and aggregate productivity in China. CEPII Working Paper No. 16.

Menon, N., \& van der Meulen Rodgers, Y. (2017). The impact of the minimum wage on male and female employment and earnings in India. Asian Development Review, 34(1), 28-64.

Mincer, J. (1976). Unemployment effects of minimum wages. Journal of Political Economy, 84(4, Pt. 2), S87-S104.

Miranda, J. (2013). Labor demand stability and the minimum wage effect on employment: The Chilean evidence. MPRA Paper No. 60333.

Montenegro, C., \& Pagés, C. (2004). Who benefits from labor market regulations? Chile, 1960-1998. In J. J. Heckman and C. Pagés (Eds.), Law and employment: Lessons from Latin American and the Caribbean (pp. 401-434). Chicago: University of Chicago Press. 
Munguía Corella, L.F. (2019). Minimum wages and enforcement effects on employment in developing countries. Unpublished paper. https://ssrn.com/abstract=3442352.

Munguía Corella, L.F. Minimum wages in monopsonistic labor markets. Forthcoming in IZA Journal of Labor Economics.

Neumark, D. (2019). The econometrics and economics of the employment effects of minimum wages: Getting from known unknowns to known knowns. German Economic Review, 20(3), 293-329.

Neumark, D. (2016). Policy levers to increase jobs and increase income from work after the Great Recession. IZA Journal of Labor Policy 5:6 (online).

Neumark, D., Cunningham, W., \& Siga, L. (2006). The effects of the minimum wage in Brazil on the distribution of family incomes: 1996-2001. Journal of Development Economics, 80(1), 136-159.

Neumark, D., \& Wascher, W. (2007). Minimum wages and employment. Foundations and Trends in Microeconomics, 3(1-2), 1-182.

Neumark, D., \& Wascher, W. (2002). State-level estimates of minimum wage effects: New evidence and interpretations from disequilibrium models. Journal of Human Resources, 37(1), 35-62

Neumark, D., \& Wascher, W. (1998). Is the time-series evidence on minimum wage effects contaminated by publication bias? Economic Inquiry, 36(3), 458-470.

Ni, J., Wang, G., \& Yao, X. (2011). Impact of minimum wages on employment. The Chinese Economy, 44(1), 18-38.

Papps, K. (2012). The effects of social security taxes and minimum wages on employment: Evidence from Turkey. ILR Review, 65(3), 686-707.

Pelek, S. (2011). The employment effect of the minimum wage on youth labour market in Turkey: A regional panel data analysis. Unpublished paper. https://www.researchgate.net/publication/228466644_The_Employment_Effect_of_the_Minimum_Wa ge_on_Youth_Labour_Market_in_Turkey_A_Regional_Panel_Data_Analysis1.

Shi, J. (2011). Employment effect of minimum wage in China - Research based on construction and manufacturing. In Q. Zhou (ed.), Advances in applied economics, business and development (pp. 78- 
82). Berlin-Heidelberg: Springer.

Strobl, E., \& Walsh, F. (2003). Minimum wages and compliance: The case of Trinidad and Tobago. Economic Development and Cultural Change, 51(2), 427-450.

Suryahadi, A., Widyanti, W., Perwira, D., \& Sumarto, S. (2003). Minimum wage policy and its impact on employment in the urban formal sector. Bulletin of Indonesian Economic Studies, 39(1), 29-50.

Wang, J., \& Gunderson, M. 2011. Minimum wage impacts in China: Estimates from a prespecified research design, 2000-2007. Contemporary Economic Policy, 29(3), 392-406.

Wang, J., \& Gunderson, M. (2012). Minimum wage effects on employment and wages: Dif-in-dif estimates from Eastern China. International Journal of Manpower, 33(8), 860-876.

Xiao, X.-Y., Xiang, B.-L. (2009). The impact of minimum wage policy on wages and employment in China. Proceedings of the 2009 International Conference on Information Management, Innovation Management and Industrial Engineering, 2, 102-105. 
Figure 1: Histogram of Estimated Elasticities in Surveyed Studies and Authors' Preferred Elasticities

\section{A. All estimates}

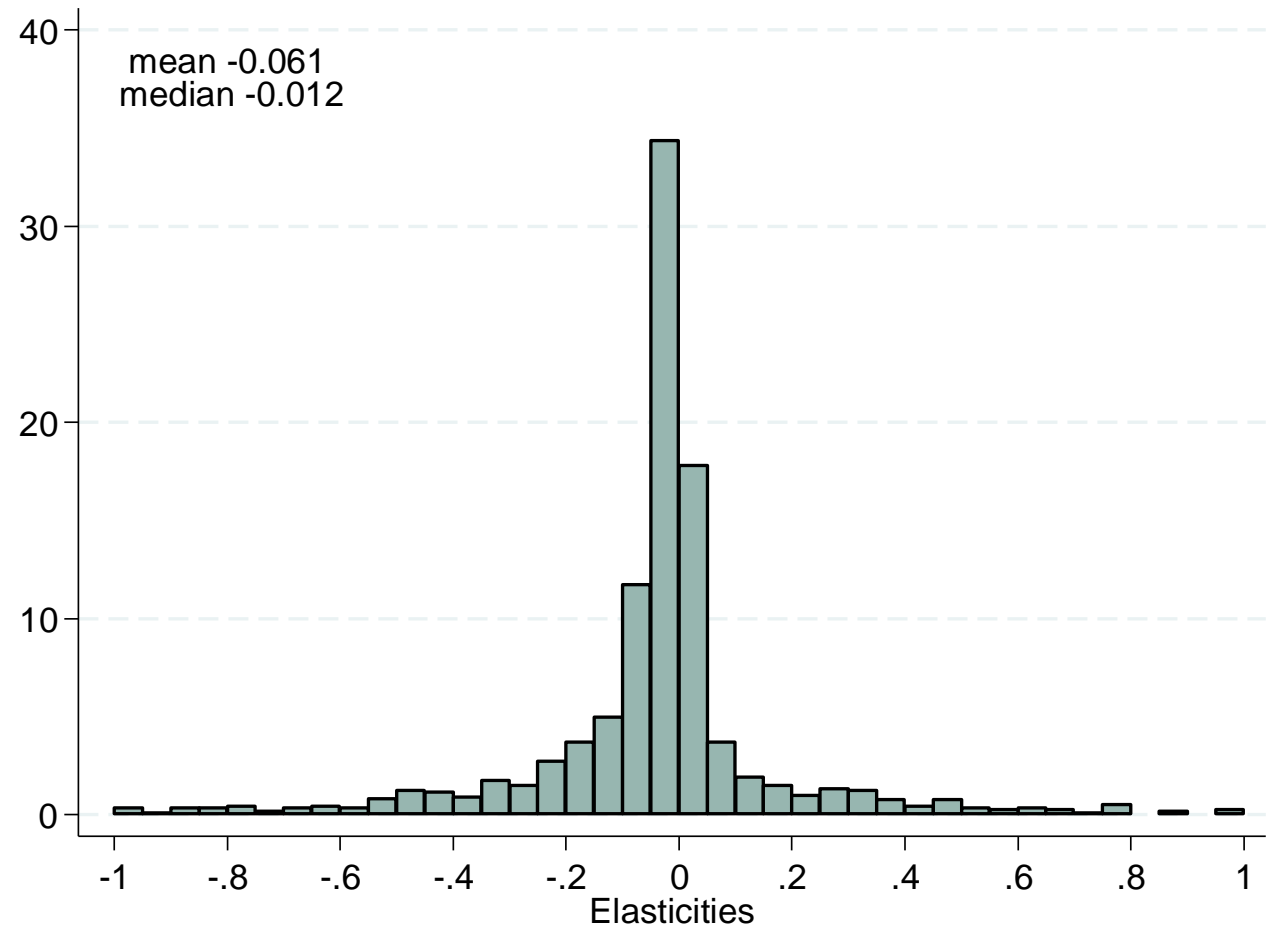

B. Authors' Preferred Estimates

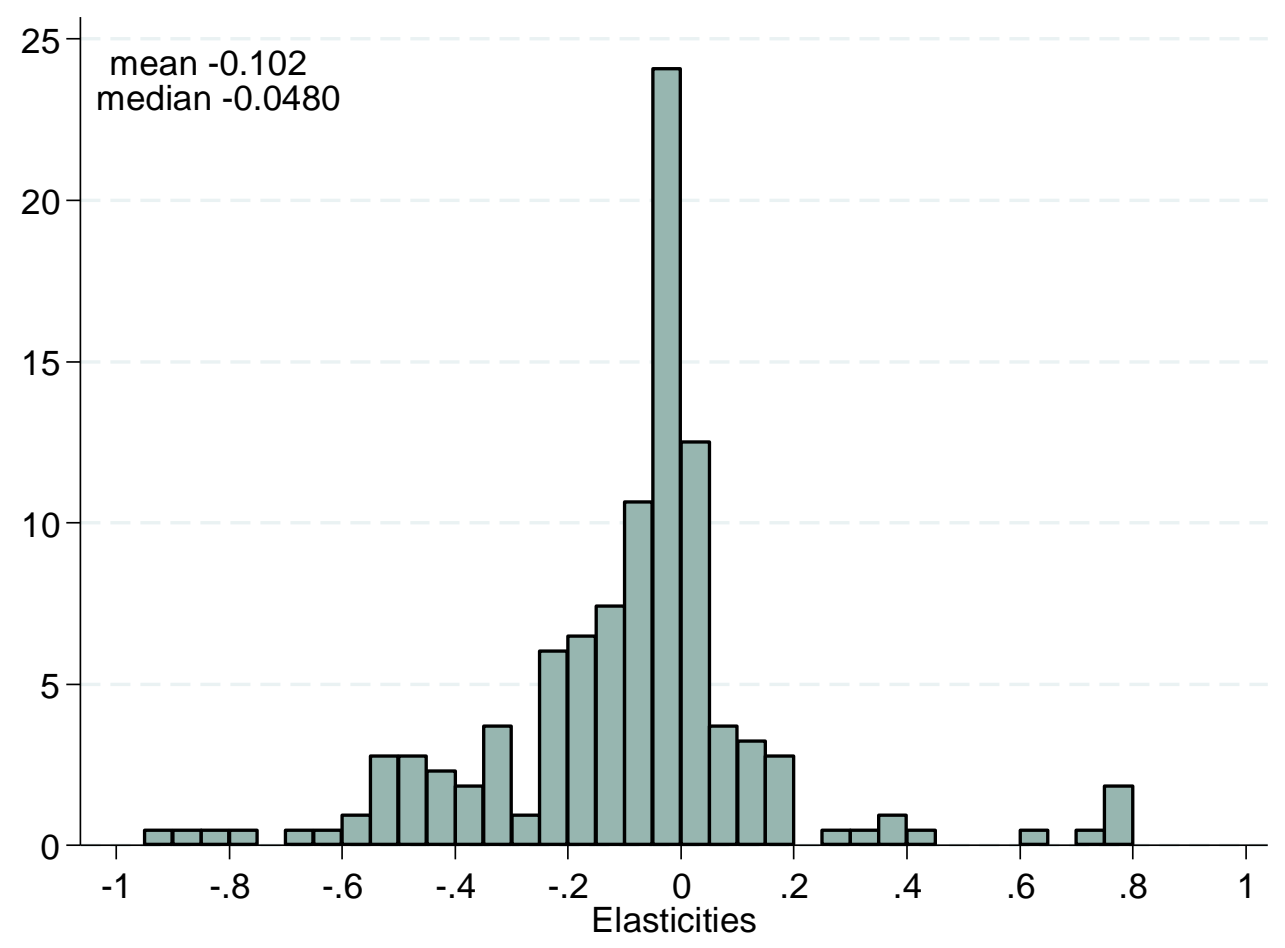

Note: We drop from the histograms (but include in the means and medians) the observations that are larger than 1 in absolute value to eliminate outliers and because most of the observations are between -1 and 1 . 
Figure 2A: Results by Features of Estimates, Authors' Preferred Estimates, Sign and Significance

A. Both features more strongly predict negative effects

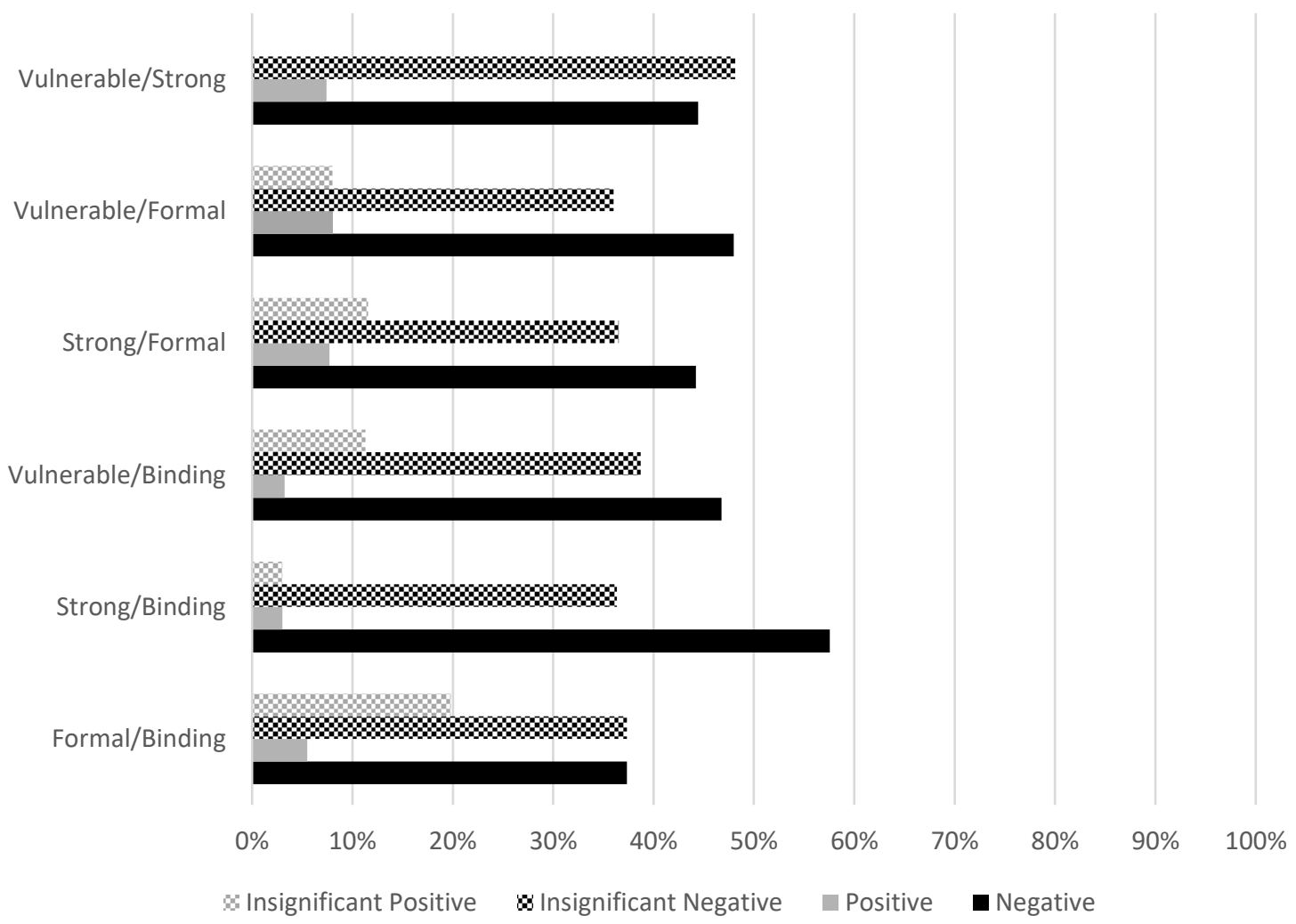

B. One feature more strongly predicts negative effects

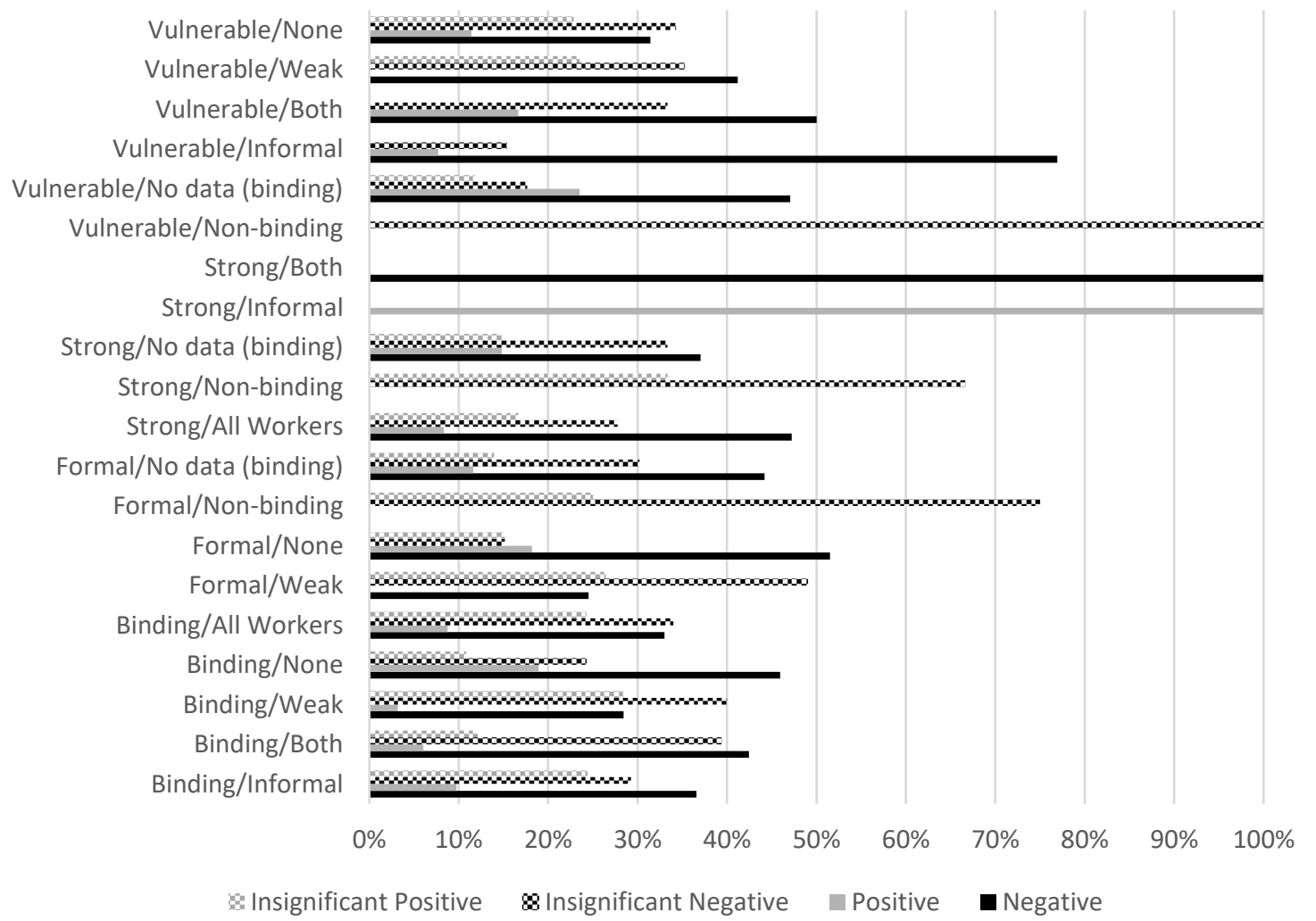




\section{Figure 2A (continued)}

\section{Neither feature more strongly predicts negative effects}

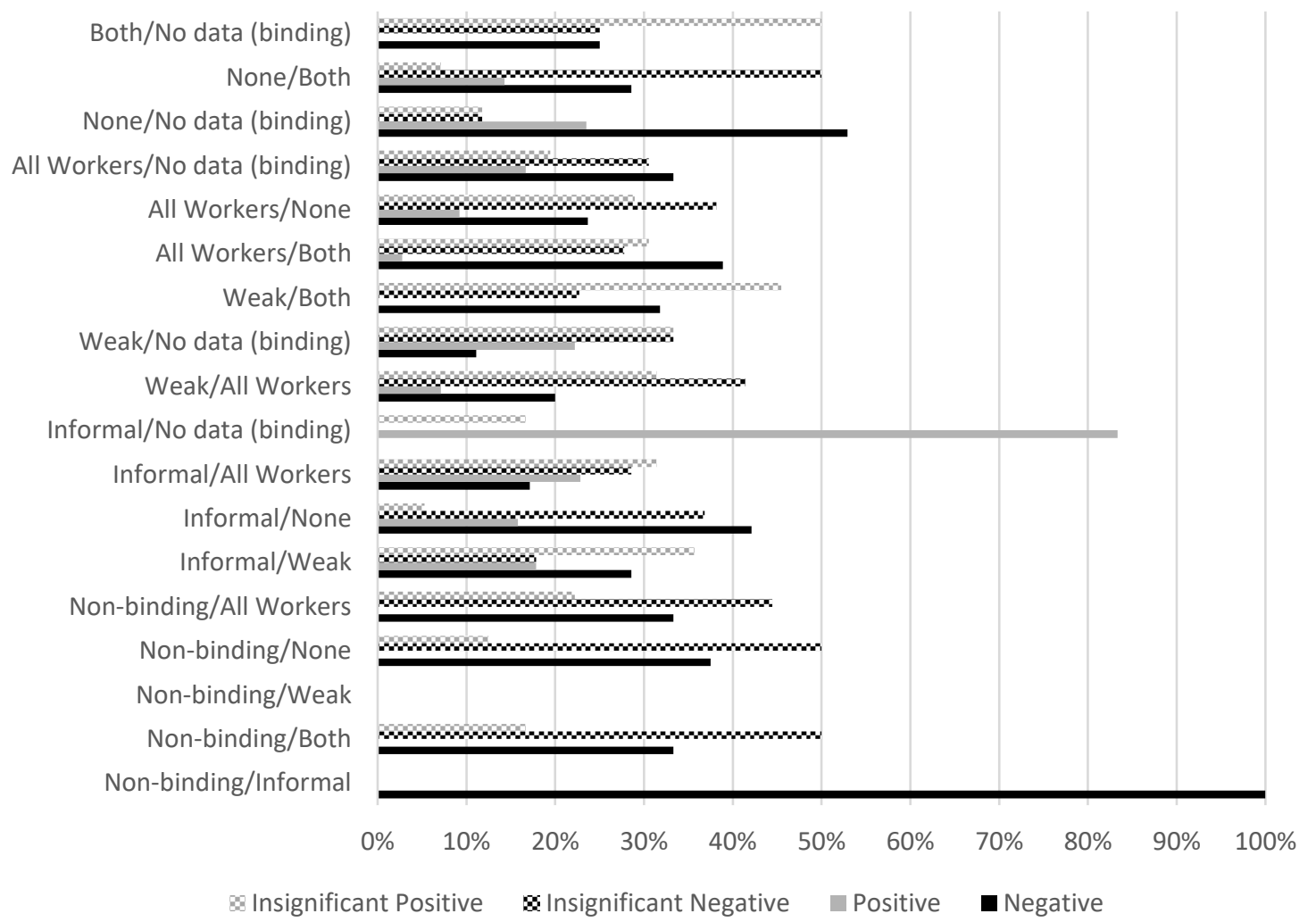

Note: Results labeled "Positive" or "Negative" have p-values $\leq 0.05$. "None" refers to no enforcement, and "Weak" to weak enforcement. "Both" refers to covering the formal and informal sectors combined. 
Figure 2B: Results by Features of Estimates, Authors' Preferred Estimates, Average Elasticities

A. Both features more strongly predict negative effects

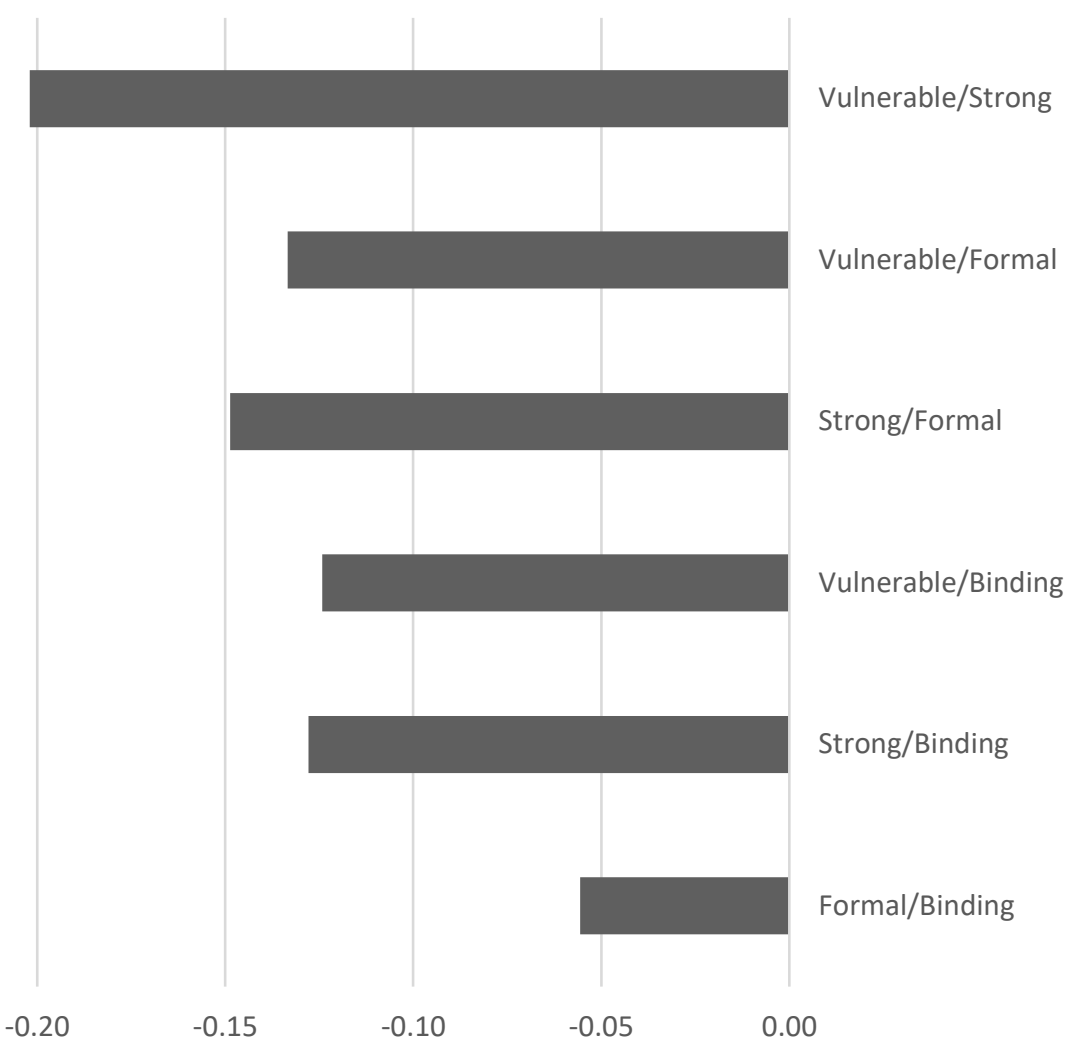

B. One feature more strongly predicts negative effects

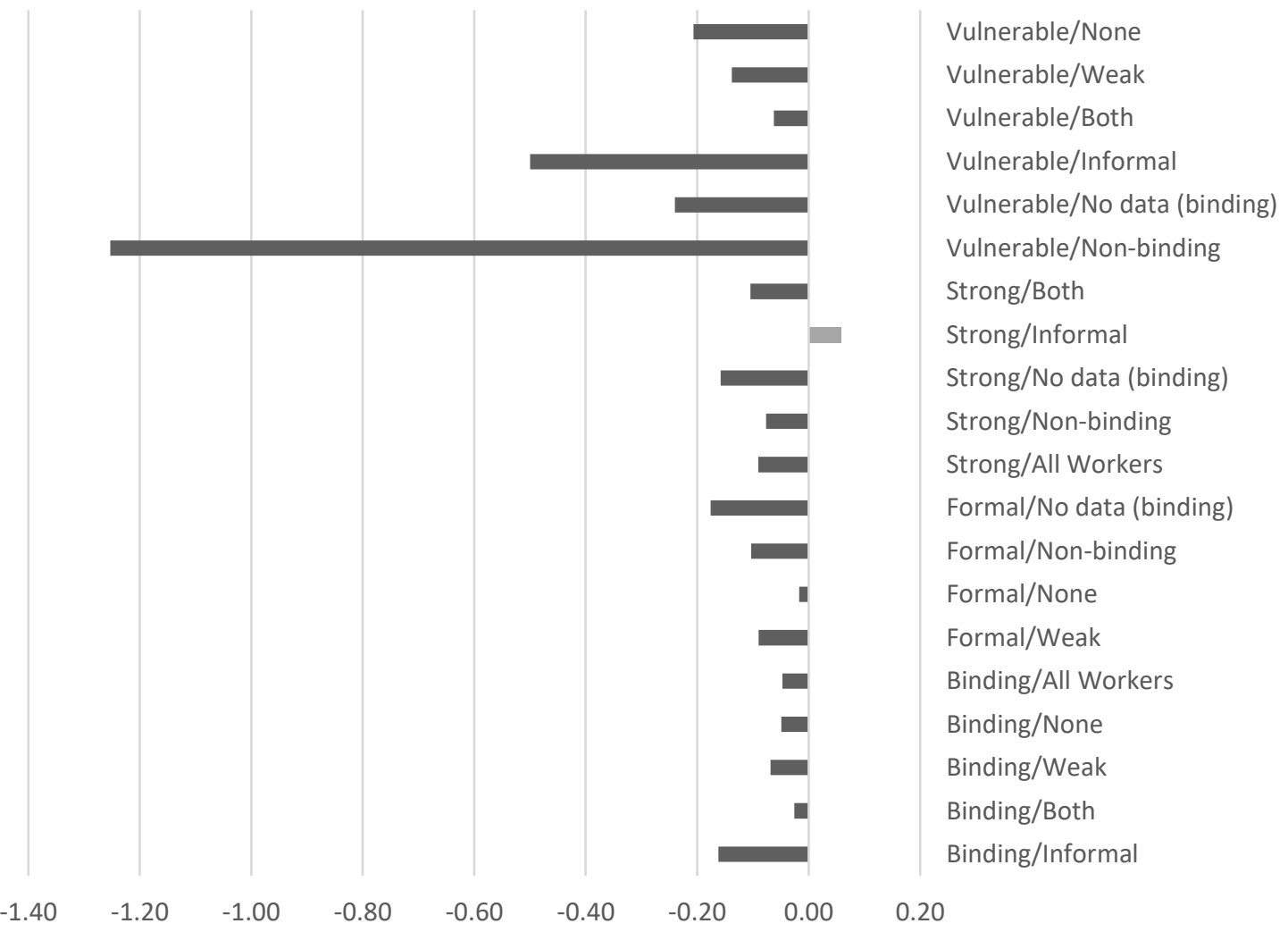




\section{Figure 2B (continued)}

\section{Neither feature more strongly predicts negative effects}

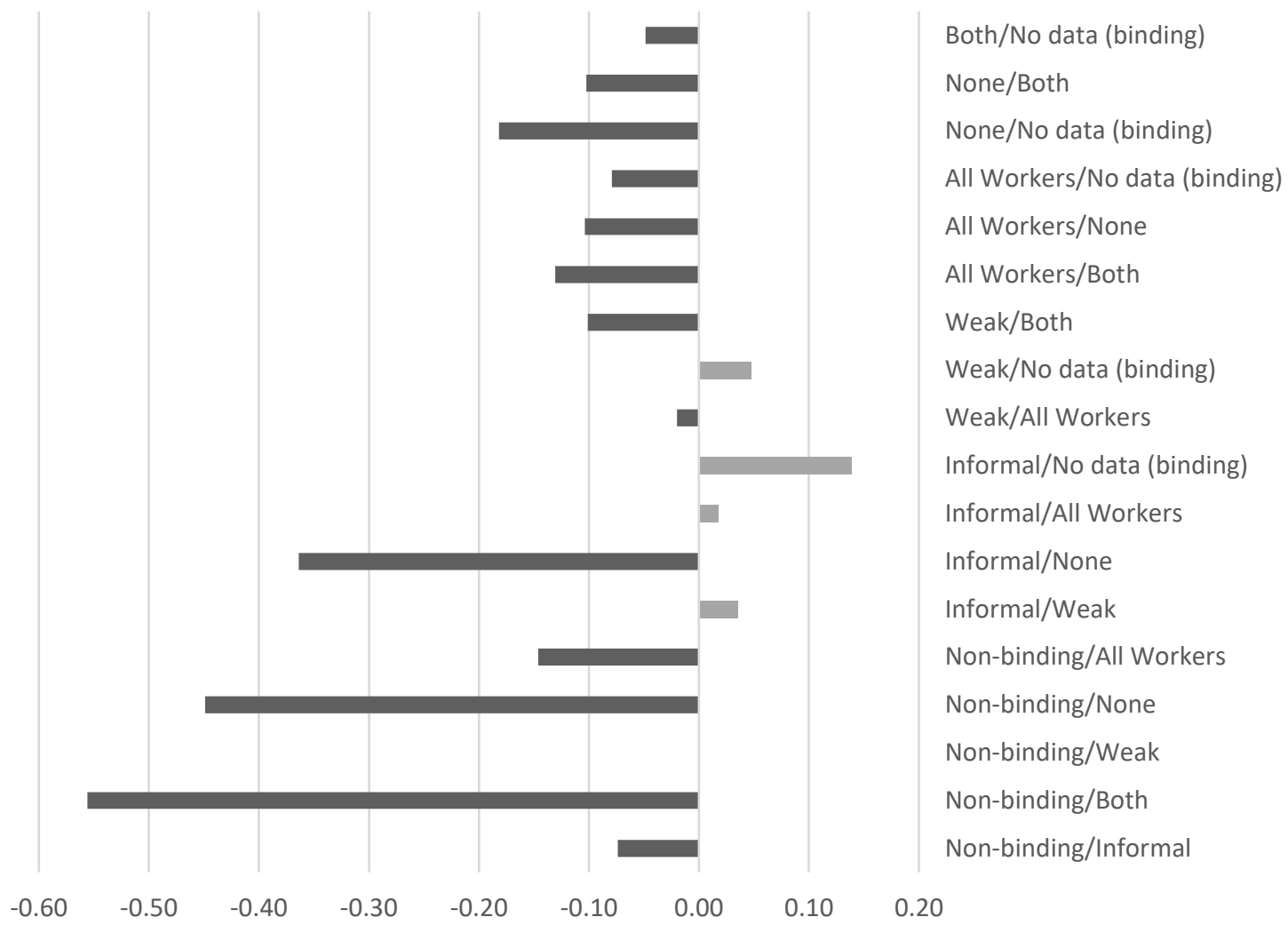

Note: See notes to Figure 2A. 
Figure 3A: Results by Features of Estimates, Authors' Preferred Estimates, Sign and Significance

A. Three or four features more strongly predict negative effects

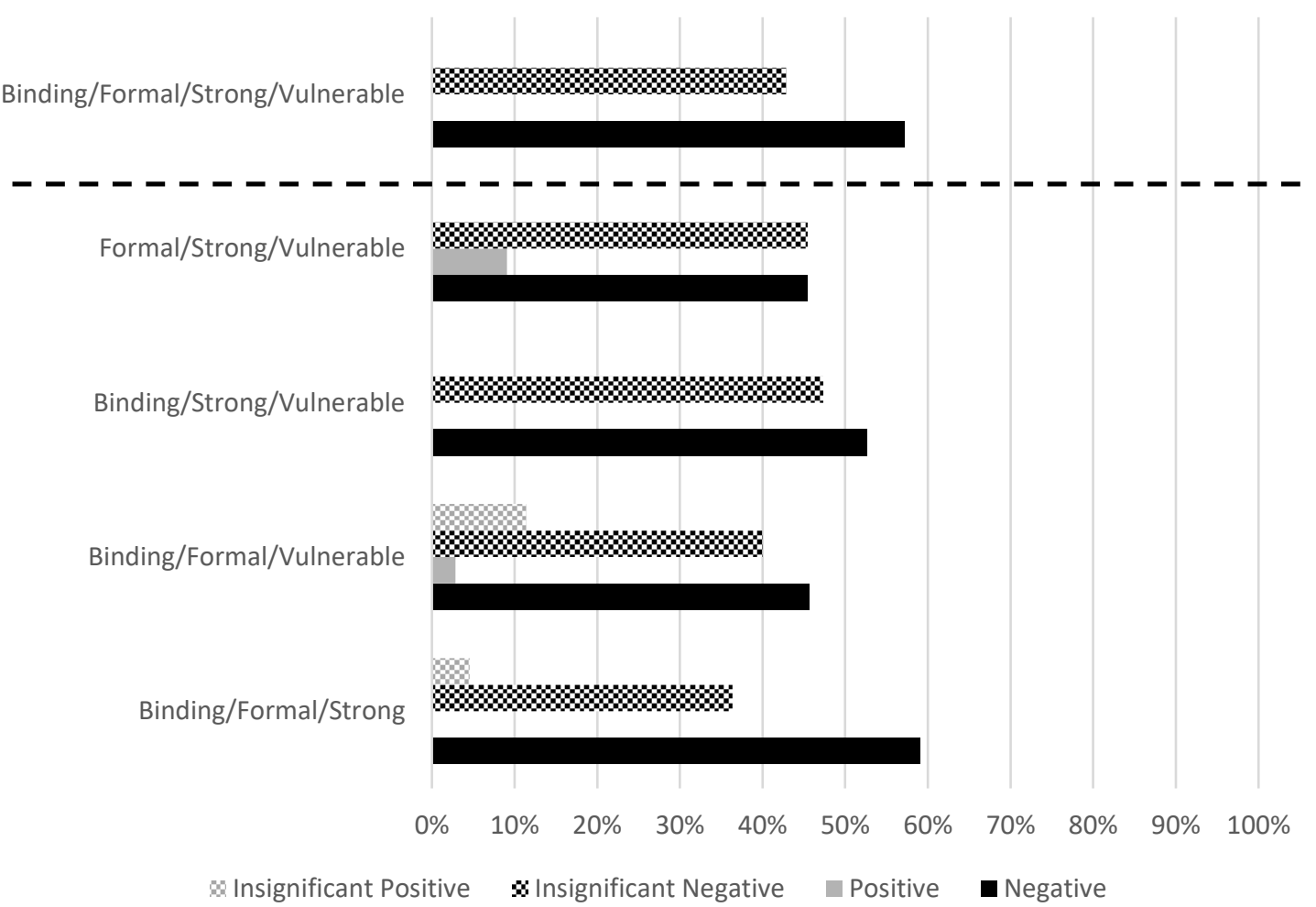

B. Three or four features do not more strongly predict negative effects

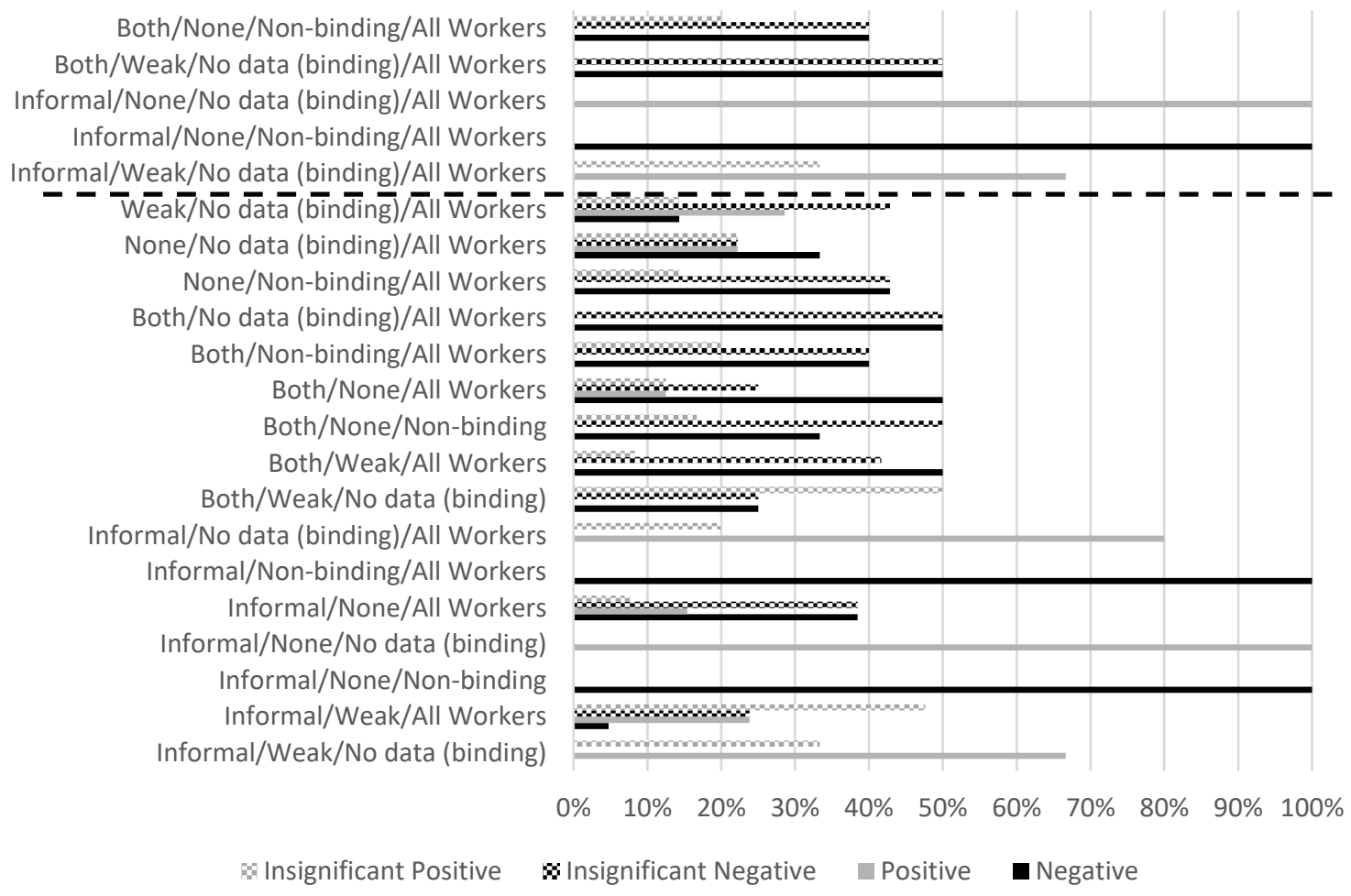

Note: Entries with no estimates are not shown. Entries above the dashed line are for four-way classifications of features of estimates. Results labeled "Positive" or "Negative" have p-values $\leq 0.05$. See notes to Figure 2A. 


\section{Figure 3B: Results by Features of Estimates, Authors' Preferred Estimates, Average Elasticities}

\section{A. Three or four features more strongly predict negative effects}

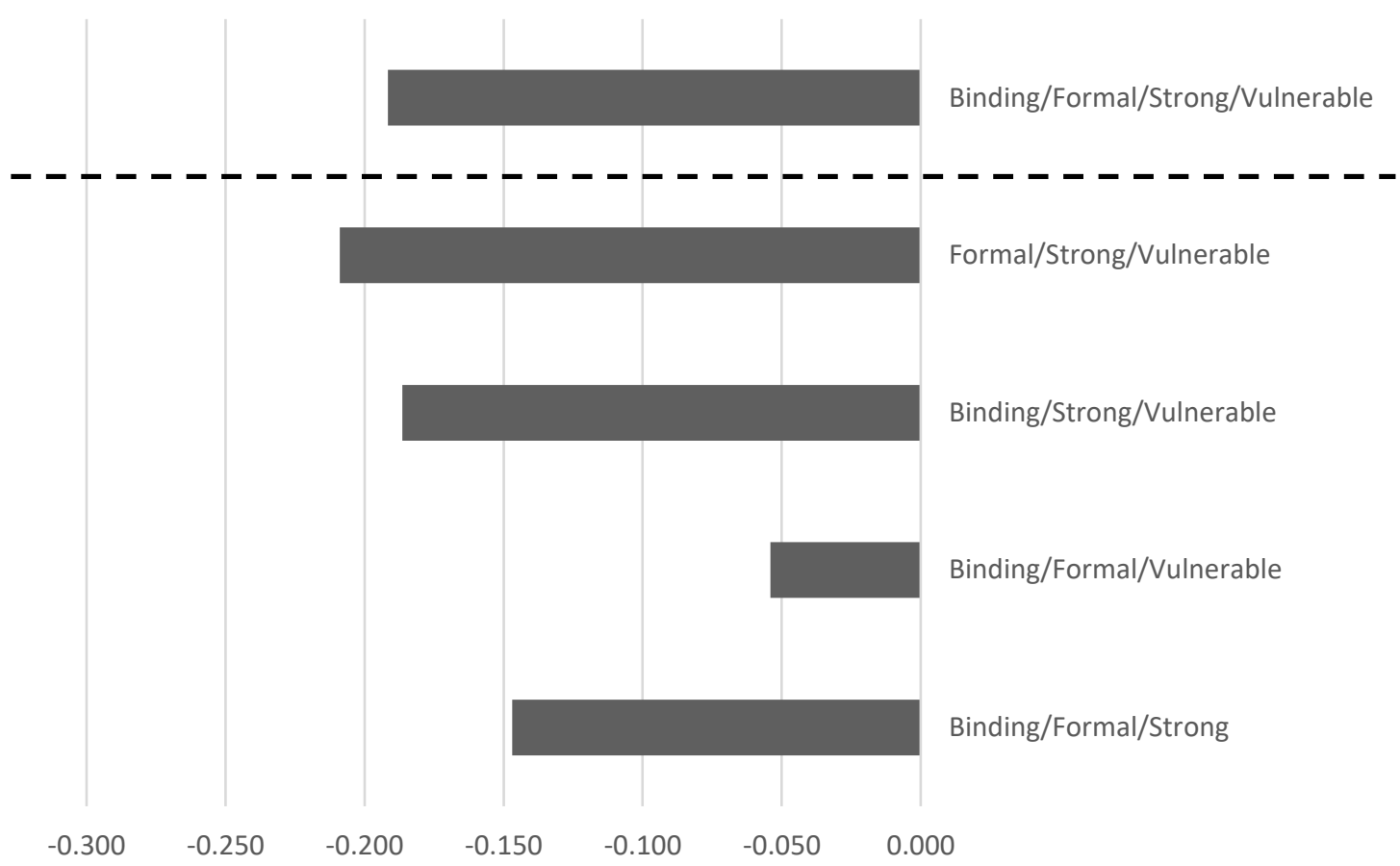

B. Three or four features do not predict stronger negative effects

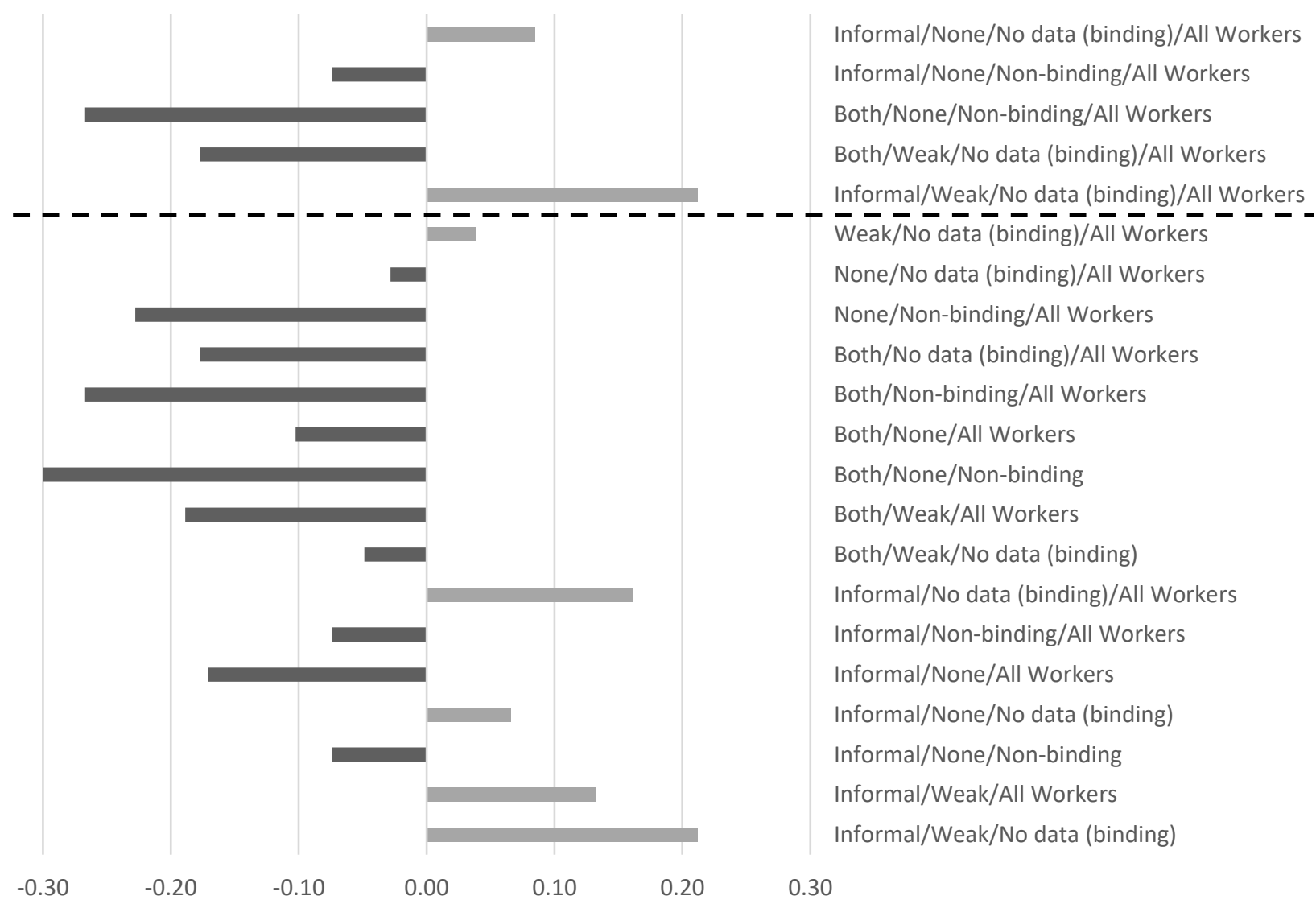

Note: Entries with no estimates are not shown. Entries above the dashed line are for four-way classifications of features of estimates. See notes to Figure 2A. 
Table 1. Summary of Estimated Elasticities from Surveyed Studies and Authors' Preferred Estimates

\begin{tabular}{|l|c|c|c|c|c|c|c|c|}
\hline & Mean & Median & Minimum & Maximum & $\begin{array}{c}\text { Standard } \\
\text { dev. }\end{array}$ & Obs. & Skewness & Kurtosis \\
\hline All estimates & -0.061 & -0.012 & -4.73 & 4.51 & 0.451 & 1,250 & -1.77 & 39.35 \\
\hline $\begin{array}{l}\text { Authors' preferred } \\
\text { estimates }\end{array}$ & -0.102 & -0.048 & -2.53 & 2.19 & 0.497 & 229 & -0.04 & 13.37 \\
\hline
\end{tabular}

Table 2. One-Way Classification of Estimation Results by Features of Estimates, Authors' Preferred Estimates

\begin{tabular}{|c|c|c|c|c|}
\hline & Negative and significant & Insignificant & Positive and significant & Total \\
\hline \multicolumn{5}{|l|}{ A. Binding } \\
\hline Binding & $63(38.2 \%)$ & $91(55.2 \%)$ & $11(6.7 \%)$ & $165(100.0 \%)$ \\
\hline Not binding & $3(27.3 \%)$ & $8(72.7 \%)$ & $0(0.0 \%)$ & $11(100.0 \%)$ \\
\hline No data & $20(37.7 \%)$ & $23(43.4 \%)$ & $10(18.9 \%)$ & $53(100.0 \%)$ \\
\hline \multicolumn{5}{|l|}{ B. Sector } \\
\hline Formal & $53(38.4 \%)$ & $75(54.3 \%)$ & $10(7.2 \%)$ & $138(100.0 \%)$ \\
\hline Informal & $16(33.3 \%)$ & $23(47.9 \%)$ & $9(18.8 \%)$ & $48(100.0 \%)$ \\
\hline Both & $17(39.5 \%)$ & $24(55.8 \%)$ & $2(4.7 \%)$ & $43(100.0 \%)$ \\
\hline \multicolumn{5}{|l|}{ C. Enforcement } \\
\hline Strong & $29(46.0 \%)$ & $29(46.0 \%)$ & $5(7.9 \%)$ & $63(100.0 \%)$ \\
\hline Weak & $28(26.9 \%)$ & $71(68.3 \%)$ & $5(4.8 \%)$ & $104(100.0 \%)$ \\
\hline No enforcement & $29(46.8 \%)$ & $22(35.5 \%)$ & $11(17.7 \%)$ & $62(100.0 \%)$ \\
\hline \multicolumn{5}{|l|}{ D. Workers } \\
\hline Vulnerable & $37(45.7 \%)$ & $38(46.9 \%)$ & $6(7.4 \%)$ & $81(100.0 \%)$ \\
\hline All workers & $49(33.1 \%)$ & $84(56.8 \%)$ & $15(10.1 \%)$ & $148(100.0 \%)$ \\
\hline
\end{tabular}

Notes: Each cell reports the number of results and the row percent (in parentheses). Each category adds to the total of 229 preferred estimates. We classify results as significant if the $p$-value $\leq 0.05$. 
Table 3. Meta-Analysis Regressions, Based on Counts of Features of Estimates More Strongly Predicting Negative Employment Effects

\begin{tabular}{|l|c|c|c|}
\hline & $(1)$ & $(2)$ & $(3)$ \\
\hline $\begin{array}{l}\text { Variables: number of features of estimates that } \\
\text { more strongly predict negative employment } \\
\text { effects }\end{array}$ & $\begin{array}{c}\text { Negative estimate } \\
(\mathrm{LPM})\end{array}$ & $\begin{array}{c}\text { Negative and } \\
\text { significant estimate } \\
(\mathrm{LPM})\end{array}$ & $\begin{array}{c}\text { Estimated } \\
\text { elasticity }\end{array}$ \\
\hline & & & -0.074 \\
\hline No estimate features & $0.538^{* * *}$ & $0.308^{* * *}$ & $(0.112)$ \\
\hline & $(0.190)$ & $(0.110)$ & -0.072 \\
\hline One estimate feature & $0.636^{* * *}$ & $0.273^{* * *}$ & $(0.055)$ \\
\hline & $(0.081)$ & $(0.070)$ & 0.991 \\
\hline One = No (p-value) & 0.645 & 0.785 & $-0.125^{* * *}$ \\
\hline Two estimate features & $0.714^{* * *}$ & $0.400^{* * *}$ & $(0.041)$ \\
\hline & $(0.051)$ & $(0.077)$ & 0.393 \\
\hline Two = One (p-value) & 0.441 & 0.197 & 0.675 \\
\hline Two = No (p-value) & 0.377 & 0.500 & -0.060 \\
\hline Three study features & $0.810^{* * *}$ & $0.405^{* * *}$ & $(0.118)$ \\
\hline & $(0.091)$ & $(0.110)$ & 0.629 \\
\hline Three = Two (p-value) & 0.292 & 0.967 & 0.937 \\
\hline Three = One (p-value) & 0.118 & 0.299 & 0.927 \\
\hline Three = No (p-value) & 0.185 & 0.527 & -0.192 \\
\hline Four estimate features & 1.000 & $0.571^{* * *}$ & $(0.127)$ \\
\hline & $(0.000)$ & $(0.039)$ & 0.433 \\
\hline Four = Three (p-value) & 0.040 & 0.188 & 0.618 \\
\hline Four = Two (p-value) & 0.000 & 0.046 & 0.391 \\
\hline Four = One (p-value) & 0.000 & 0.000 & 0.490 \\
\hline Four = No (p-value) & 0.018 & 0.027 & 0.782 \\
\hline Joint test: Four = Three $=$ Two = One (p-value) & 0.000 & 0.004 & 229 \\
\hline Observations & 229 & 229 & \\
\hline p & & & \\
\hline
\end{tabular}

${ }^{* * * *} \mathrm{p}<0.01,{ }^{* *} \mathrm{p}<0.05,{ }^{*} \mathrm{p}<0.1$. There are 229 observations.

Note: The table reports estimates of equation (1). LPM = linear probability model. The variables are defined to be mutually exclusive. For the LPMs, standard errors are clustered by study. There are 61 clusters. Note that for the estimates in column (1), there is no variation in the dependent variable for the "Four estimate features" variables, which is why there is no variation in the estimated coefficient. 
Table 4. Meta-Analysis Regressions, Testing Specific Features of Estimates More Strongly Predicting Negative Employment Effect, Conditional on Number of Such Features

\begin{tabular}{|c|c|c|c|c|c|c|c|c|c|c|c|c|}
\hline & (1) & (2) & (3) & (4) & (5) & (6) & (7) & (8) & (9) & (10) & (11) & (12) \\
\hline & $\begin{array}{l}\text { Negative } \\
\text { estimate } \\
\text { (LPM) }\end{array}$ & $\begin{array}{l}\text { Neg. and } \\
\text { sign. est. } \\
\text { (LPM) }\end{array}$ & $\begin{array}{l}\text { Estimated } \\
\text { elasticity }\end{array}$ & $\begin{array}{l}\text { Negative } \\
\text { estimate } \\
\text { (LPM) }\end{array}$ & $\begin{array}{l}\text { Neg. and } \\
\text { sign. est. } \\
\text { (LPM) }\end{array}$ & $\begin{array}{l}\text { Estimated } \\
\text { elasticity }\end{array}$ & $\begin{array}{l}\text { Negative } \\
\text { estimate } \\
\text { (LPM) }\end{array}$ & $\begin{array}{l}\text { Neg. and } \\
\text { sign. est. } \\
\text { (LPM) }\end{array}$ & $\begin{array}{l}\text { Estimated } \\
\text { elasticity }\end{array}$ & $\begin{array}{l}\text { Negative } \\
\text { estimate } \\
\text { (LPM) }\end{array}$ & $\begin{array}{l}\text { Neg. and } \\
\text { sign. est. } \\
\text { (LPM) }\end{array}$ & $\begin{array}{l}\text { Estimated } \\
\text { elasticity }\end{array}$ \\
\hline Feature: & \multicolumn{3}{|c|}{ Binding } & \multicolumn{3}{|c|}{ Formal sector } & \multicolumn{3}{|c|}{ Strong enforcement } & \multicolumn{3}{|c|}{ Vulnerable workers } \\
\hline $\begin{array}{l}\text { Variables: number of estimate features } \\
\text { that more strongly predict negative } \\
\text { employment effects }\end{array}$ & & & & & & & & & & & & \\
\hline No estimate features & $0.538 * * *$ & $0.308 * * *$ & -0.074 & $0.538 * * *$ & $0.308 * * *$ & -0.074 & $0.538 * * *$ & $0.308 * * *$ & -0.074 & $0.538 * * *$ & $0.308 * * *$ & -0.074 \\
\hline \multirow[t]{2}{*}{ One estimate feature (includes feature) } & $0.634 * * *$ & $0.293 * * *$ & -0.038 & $0.800 * * *$ & $0.300^{*}$ & $-0.062 * *$ & - & - & - & 0.250 & 0.000 & -0.452 \\
\hline & $(0.102)$ & $(0.088)$ & $(0.059)$ & $(0.156)$ & $(0.153)$ & $(0.025)$ & & & & $(0.239)$ & $(0.000)$ & $(0.496)$ \\
\hline \multirow[t]{2}{*}{ One estimate feature (excludes feature) } & $0.643 * * *$ & $0.214 * *$ & -0.174 & $0.600 * * *$ & $0.267 * * *$ & -0.075 & $0.636 * * *$ & $0.273 * * *$ & -0.072 & $0.667 * * *$ & $0.294 * * *$ & -0.043 \\
\hline & $(0.133)$ & $(0.107)$ & $(0.147)$ & $(0.095)$ & $(0.081)$ & $(0.067)$ & $(0.082)$ & $(0.071)$ & $(0.055)$ & $(0.088)$ & $(0.077)$ & $(0.048)$ \\
\hline $\begin{array}{l}\text { Equal coefficients for one estimate } \\
\text { feature ( } \mathrm{p} \text {-value) }\end{array}$ & 0.960 & 0.575 & 0.405 & 0.286 & 0.849 & 0.859 & 0 & 0 & 0.193 & 0.132 & 0 & 0.416 \\
\hline \multirow[t]{2}{*}{ Two estimate features (includes feature) } & $0.711 * * *$ & $0.368 * * *$ & $-0.101 * * *$ & $0.675 * * *$ & $0.351 * * *$ & $-0.105^{*}$ & $0.714 * * *$ & $0.429 * * *$ & $-0.097 * *$ & $0.828 * * *$ & $0.586 * * *$ & $-0.269 * *$ \\
\hline & $(0.063)$ & $(0.089)$ & $(0.036)$ & $(0.061)$ & $(0.082)$ & $(0.054)$ & $(0.077)$ & $(0.118)$ & $(0.042)$ & $(0.088)$ & $(0.139)$ & $(0.117)$ \\
\hline Two estimate features (excludes feature) & $0.724 * * *$ & $0.483 * * *$ & $-0.188^{*}$ & $0.821 * * *$ & $0.536 * * *$ & $-0.181 * *$ & $0.714 * * *$ & $0.390 * * *$ & $-0.135 * *$ & $0.671 * * *$ & $0.329 * * *$ & $-0.070 * *$ \\
\hline $\begin{array}{l}\text { Equal coefficients for two estimate } \\
\text { features (p-value) }\end{array}$ & 0.898 & 0.511 & 0.445 & 0.182 & 0.184 & 0.482 & 1 & 0.799 & 0.578 & 0.151 & 0.078 & 0.121 \\
\hline \multirow[t]{2}{*}{ Three estimate features (includes feature) } & $0.824 * * *$ & $0.441 * * *$ & -0.018 & $0.784 * * *$ & $0.405 * * *$ & -0.045 & $0.857 * * *$ & $0.429 * * *$ & $-0.158 * *$ & $0.794 * * *$ & $0.353 * * *$ & -0.058 \\
\hline & $(0.100)$ & $(0.130)$ & $(0.142)$ & $(0.102)$ & $(0.117)$ & $(0.134)$ & $(0.099)$ & $(0.143)$ & $(0.065)$ & $(0.109)$ & $(0.120)$ & $(0.146)$ \\
\hline \multirow[t]{2}{*}{ Three estimate features (excludes feature) } & $0.750 * * *$ & $0.250 *$ & $-0.239 *$ & $1.000 * * *$ & 0.400 & $-0.172 * *$ & $0.762 * * *$ & $0.381 * *$ & 0.038 & $0.875 * * *$ & $0.625 * *$ & -0.069 \\
\hline & $(0.222)$ & $(0.128)$ & $(0.122)$ & $(0.000)$ & $(0.307)$ & $(0.077)$ & $(0.150)$ & $(0.169)$ & $(0.225)$ & $(0.111)$ & $(0.239)$ & $(0.070)$ \\
\hline $\begin{array}{l}\text { Equal coefficients for three estimate } \\
\text { features (p-value) }\end{array}$ & 0.764 & 0.300 & 0.243 & 0.038 & 0.989 & 0.417 & 0.598 & 0.830 & 0.407 & 0.603 & 0.308 & 0.949 \\
\hline \multirow[t]{2}{*}{ Four estimate features } & 1.000 & $0.571 * * *$ & -0.192 & 1.000 & $0.571 * * *$ & -0.192 & 1.000 & $0.571 * * *$ & -0.192 & 1.000 & $0.571 * * *$ & -0.192 \\
\hline & $(0.000)$ & $(0.039)$ & $(0.127)$ & $(0.000)$ & $(0.039)$ & $(0.127)$ & $(0.000)$ & $(0.039)$ & $(0.127)$ & $(0.000)$ & $(0.039)$ & $(0.127)$ \\
\hline Observations & 229 & 229 & 229 & 229 & 229 & 229 & 229 & 229 & 229 & 229 & 229 & 229 \\
\hline
\end{tabular}

${ }^{*} \mathrm{p}<0.01,{ }^{* *} \mathrm{p}<0.05,{ }^{*} \mathrm{p}<0.1$. Standard errors are clustered by study. There are 61 clusters and 229 observations.

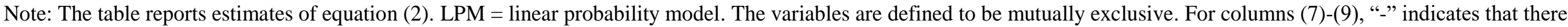

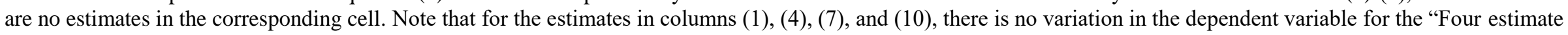
features" variables, which is why there is no variation in the estimated coefficient. 
Table 5. Standard Meta-Analysis Regressions, Testing Specific Features of Estimates More Strongly Predicting Negative Employment Effect

\begin{tabular}{|l|c|c|c|c|c|c|}
\hline & $(1)$ & $(2)$ & $(3)$ & $(4)$ & $(5)$ & $(6)$ \\
\hline & $\begin{array}{c}\text { Negative } \\
\text { estimate } \\
(\text { LPM })\end{array}$ & $\begin{array}{c}\text { Neg. and } \\
\text { sign. est. } \\
\text { (LPM) }\end{array}$ & $\begin{array}{c}\text { Estimated } \\
\text { elasticity }\end{array}$ & $\begin{array}{c}\text { Negative } \\
\text { estimate } \\
\text { (LPM) }\end{array}$ & $\begin{array}{c}\text { Neg. and } \\
\text { sign. est. } \\
\text { (LPM) }\end{array}$ & $\begin{array}{c}\text { Estimated } \\
\text { elasticity }\end{array}$ \\
\hline Binding & -0.017 & 0.252 & 0.294 & 0.105 & 0.045 & 0.103 \\
\hline No data on binding & $(0.126)$ & $(0.165)$ & $(0.225)$ & $(0.073)$ & $(0.091)$ & $(0.086)$ \\
\hline & -0.186 & 0.164 & 0.243 & & & \\
\hline Strong enforcement & $(0.133)$ & $(0.166)$ & $(0.198)$ & & & \\
\hline & 0.092 & -0.031 & -0.023 & $0.148^{* *}$ & 0.119 & -0.023 \\
\hline Weak enforcement & $(0.105)$ & $(0.117)$ & $(0.128)$ & $(0.068)$ & $(0.097)$ & $(0.066)$ \\
\hline & -0.083 & $-0.252^{*}$ & 0.028 & & & \\
\hline Formal sector & $(0.117)$ & $(0.140)$ & $(0.102)$ & & & \\
\hline & 0.135 & 0.021 & 0.065 & 0.041 & -0.005 & 0.043 \\
\hline All sectors & $(0.127)$ & $(0.094)$ & $(0.176)$ & $(0.087)$ & $(0.067)$ & $(0.101)$ \\
\hline & 0.159 & 0.069 & 0.079 & & & \\
\hline Vulnerable workers & $(0.152)$ & $(0.153)$ & $(0.190)$ & & & \\
\hline & 0.117 & 0.099 & $-0.130 * *$ & $0.124 *$ & 0.112 & $-0.122^{* *}$ \\
\hline Minimum wage (baseline & $(0.071)$ & $(0.115)$ & $(0.058)$ & $(0.068)$ & $(0.106)$ & $(0.057)$ \\
\hline & $0.636 * * *$ & 0.218 & -0.384 & $0.536^{* * *}$ & $0.274 * * *$ & -0.153 \\
\hline Observations & $(0.151)$ & $(0.172)$ & $(0.254)$ & $(0.086)$ & $(0.078)$ & $(0.102)$ \\
\hline
\end{tabular}

${ }^{* * *} \mathrm{p}<0.01,{ }^{* *} \mathrm{p}<0.05,{ }^{*} \mathrm{p}<0.1$. Standard errors are clustered by study. There are 61 clusters and 229 observations.

Note: $L P M=$ linear probability model. 
Appendix Figure A1: Histogram of Surveyed Studies by Year

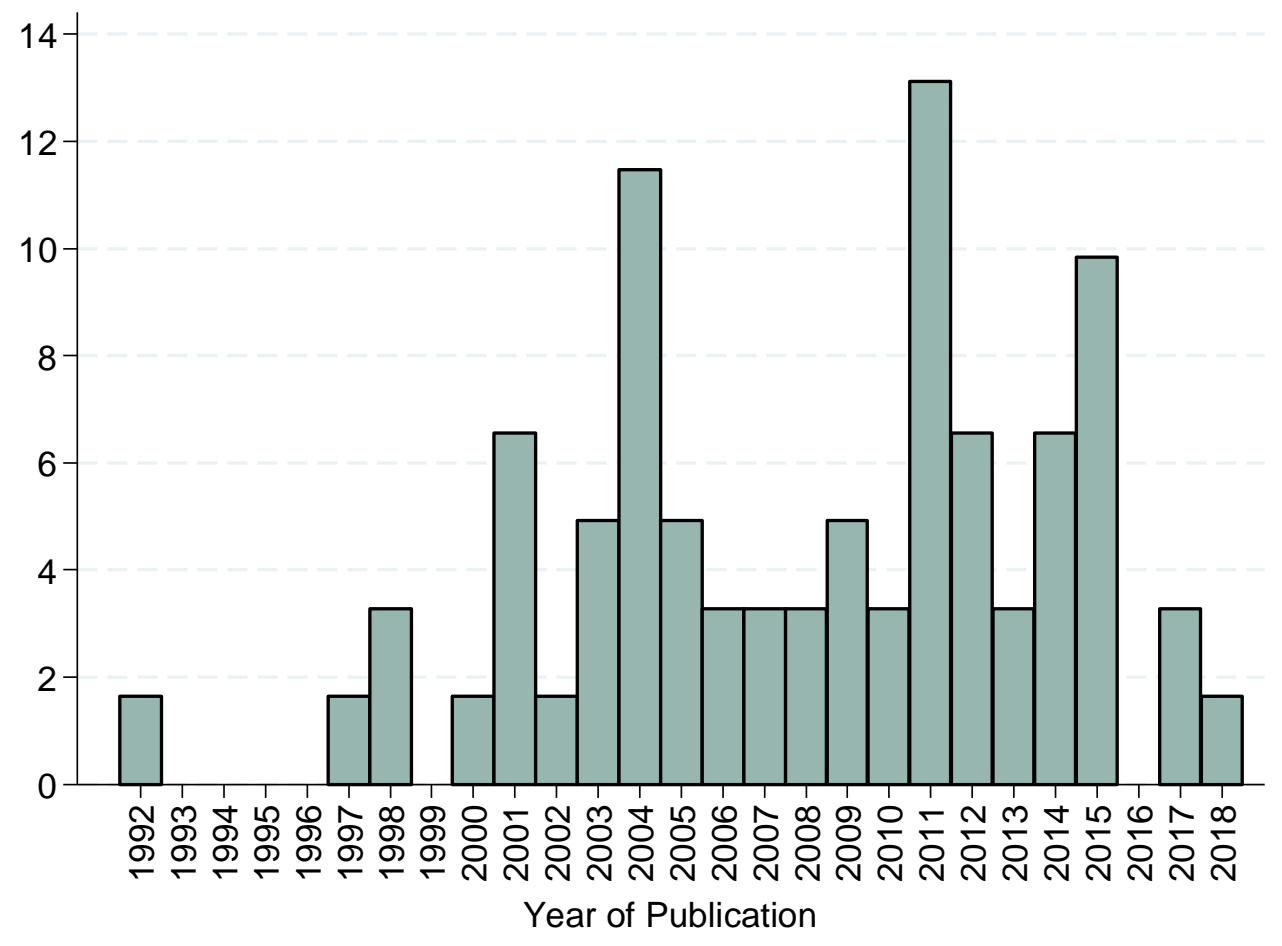


Appendix Table A1. Calculated Elasticities for Studies Not Estimating Elasticities

\begin{tabular}{|c|c|c|c|c|c|c|}
\hline Study & Country & $\begin{array}{c}\text { Minimum wage } \\
\text { variable }\end{array}$ & Period & $\begin{array}{l}\text { Avg. empl. } \\
\text { rate } \\
\end{array}$ & $\begin{array}{l}\text { Avg. } \\
\text { MW }\end{array}$ & Comments \\
\hline $\begin{array}{l}\text { Alaniz et al. } \\
(2011)\end{array}$ & Nicaragua & $\ln (\mathrm{MW})$ & $\begin{array}{l}1998- \\
2006\end{array}$ & $\begin{array}{l}\text { Varies by } \\
\text { group }\end{array}$ & -- & $\begin{array}{l}\text { The paper provides the total number of workers, the proportion of each } \\
\text { group in the total, and the sample size including the non-employed. We } \\
\text { use this information to calculate the employment rate by group. }\end{array}$ \\
\hline $\begin{array}{l}\text { Arango and } \\
\text { Pachón } \\
(2004)\end{array}$ & Colombia & MW & $\begin{array}{l}1984- \\
2001\end{array}$ & 0.74 & $202,778.4$ & $\begin{array}{l}\text { The minimum wage variable is the ratio (minimum wage)/(median } \\
\text { income), so the elasticity calculation requires the mean of this variable. } \\
\text { We do not have that, but we have median income from the paper, and } \\
\text { obtain the average minimum wage from ILO, for the period } 1991-2001 \text {. } \\
\text { The paper estimates the effects on paid and self-employed workers. We } \\
\text { calculate the employment rate from Table } 2 \text {, which reports the number } \\
\text { of paid and self-employed workers and the total sample including non- } \\
\text { workers. }\end{array}$ \\
\hline $\begin{array}{l}\text { Baranowska- } \\
\text { Rataj and } \\
\text { Magda (2015) }\end{array}$ & Poland & $\ln (\mathrm{MW})$ & $\begin{array}{l}2003- \\
2011\end{array}$ & $\begin{array}{l}0.78 \text { for } \\
\text { total, varies } \\
\text { for the rest } \\
\text { of the } \\
\text { groups }\end{array}$ & -- & $\begin{array}{l}\text { We estimate the average employment rate by group to retrieve the } \\
\text { elasticity. The paper reports total employment, the shares in each } \\
\text { category (gender, type of worker, etc.), and the sample size. }\end{array}$ \\
\hline $\begin{array}{l}\text { Bhorat et al. } \\
(2014)\end{array}$ & $\begin{array}{l}\text { South } \\
\text { Africa }\end{array}$ & $\ln (\mathrm{MW})$ & $\begin{array}{l}2000- \\
2007\end{array}$ & 0.40 & -- & $\begin{array}{l}\text { This paper studies the share of workers by industry. We calculate the } \\
\text { average number of workers in the treatment (Table } 1 \text { ) and in the control } \\
\text { (Table } 2 \text { ) per year and calculate the average employment rate } \\
\text { (Treatment/Control+Treatment). }\end{array}$ \\
\hline $\begin{array}{l}\text { Carneiro and } \\
\text { Corseuil } \\
(2001)\end{array}$ & Brazil & $\ln (\mathrm{MW})$ & $\begin{array}{l}1995- \\
1999\end{array}$ & $\begin{array}{c}\text { Varies by } \\
\text { year }\end{array}$ & -- & $\begin{array}{l}\text { We use ILOSTAT data to calculate average the formal employment rate } \\
\text { by year. We do not have data on informal employment in the same } \\
\text { range of years, but we have the ratio of formal to informal employment } \\
\text { and use this ratio to estimate employment by sector. The formal to } \\
\text { informal ratio is estimated with } 2009 \text { data (the first year reported in ILO } \\
\text { for Brazil), so we are assuming that this ratio was the same in the } \\
\text { sample period. }\end{array}$ \\
\hline $\begin{array}{l}\text { Del Carpio et } \\
\text { al. (2014) }\end{array}$ & Thailand & $\ln (\mathrm{MW})$ & $\begin{array}{l}1998- \\
2010\end{array}$ & $\begin{array}{l}\text { Varies by } \\
\text { group. For } \\
\text { the total is } \\
\quad 0.71 \text {. }\end{array}$ & -- & $\begin{array}{l}\text { We use information from ILOSTAT to calculate the employment rate by } \\
\text { group. The average employment rate in this period for all workers is } \\
0.71 \text {, and the rate varies across groups. We estimate employment rates } \\
\text { by gender and age. However, we could not determine the rates by } \\
\text { education level; thus, we applied the total employment rate }(0.71) \text { to } \\
\text { retrieve the elasticity for education groups. }\end{array}$ \\
\hline $\begin{array}{l}\text { Gindling and } \\
\text { Terrell (2007) }\end{array}$ & $\begin{array}{c}\text { Costa } \\
\text { Rica }\end{array}$ & $\ln (\mathrm{MW})$ & $\begin{array}{c}1988- \\
2000\end{array}$ & 0.625 & -- & $\begin{array}{l}\text { We use data from Table } 2 \text { in the paper to estimate the average } \\
\text { employment rate for total workers. }\end{array}$ \\
\hline $\begin{array}{l}\text { Grau and } \\
\text { Landerretche } \\
(2011)\end{array}$ & Chile & $\ln (\mathrm{MW})$ & $\begin{array}{l}1996- \\
2005\end{array}$ & 0.91 & -- & $\begin{array}{l}\text { We do not have enough information from the paper, so we use data from } \\
\text { ILOSTAT for the corresponding period. We estimate the employment } \\
\text { rate by dividing the number of employed workers by the working-age } \\
\text { population. }\end{array}$ \\
\hline Ham (2018) & Colombia & $\ln (\mathrm{MW})$ & $\begin{array}{l}1996- \\
2000\end{array}$ & $\begin{array}{l}0.97 \text { total } \\
\text { employment } \\
0.95 \text { formal } \\
0.99 \\
\text { informal } \\
\end{array}$ & -- & The paper provides the employment rates by sector in Table 2 . \\
\hline $\begin{array}{l}\text { Hohberg and } \\
\text { Lay (2015) }\end{array}$ & Indonesia & $\ln (\mathrm{MW})$ & $\begin{array}{l}1997- \\
2007\end{array}$ & 0.664 & -- & The paper reports the employment rates in Table 1. \\
\hline $\begin{array}{l}\text { Maloney and } \\
\text { Nuñez } \\
\text { Mendez } \\
(2004)\end{array}$ & Colombia & $\ln (\mathrm{MW})$ & $\begin{array}{l}1997- \\
1999\end{array}$ & -- & -- & $\begin{array}{l}\text { The authors use dummies for brackets of the initial individual wage } \\
\text { relative to the minimum wage, to estimate the impact of a change in the } \\
\text { minimum wage throughout the wage distribution. Hence, the non- } \\
\text { employed are not included, and they estimate the effect of the minimum } \\
\text { wage on the share in each bracket. We use the shares in the brackets to } \\
\text { retrieve the elasticity (Table } 2 \text { ). Also, the authors estimate and report an } \\
\text { average employment elasticity of }-0.15 \text {. (This is not stated in any table; } \\
\text { it is a calculation reported by the authors in the results section.) We use } \\
\text { the average elasticity calculated by the authors and our estimations of } \\
\text { the elasticities by brackets. }\end{array}$ \\
\hline $\begin{array}{l}\text { Menon and } \\
\text { Meulen } \\
\text { Rodgers } \\
(2017)\end{array}$ & India & $\ln (\mathrm{MW})$ & $\begin{array}{l}1983- \\
2008\end{array}$ & $\begin{array}{l}\text { Varies by } \\
\text { group }\end{array}$ & -- & $\begin{array}{l}\text { We use data from ILOSTAT to estimate the employment rate of female } \\
\text { and male workers in India with information by region (urban and rural). } \\
\text { We only have data from the period 1994-2010. }\end{array}$ \\
\hline $\begin{array}{l}\text { Montenegro } \\
\text { and Pagés } \\
(2004)\end{array}$ & Chile & $\ln (\mathrm{MW})$ & $\begin{array}{c}1960- \\
1998\end{array}$ & $\begin{array}{l}\text { Varies by } \\
\text { group }\end{array}$ & -- & $\begin{array}{l}\text { The paper gives the number of workers, but does not provide } \\
\text { information on workers by age, skill level, and gender. We estimate the } \\
\text { employment rate by group using information from ILOSTAT. The data } \\
\text { are from } 1998 \text { only (we could not find data before this year). }\end{array}$ \\
\hline
\end{tabular}




\begin{tabular}{|l|c|c|c|c|c|l|}
\hline Study & Country & $\begin{array}{c}\text { Minimum wage } \\
\text { variable }\end{array}$ & Period & $\begin{array}{c}\text { Avg. empl. } \\
\text { rate }\end{array}$ & $\begin{array}{c}\text { Avg. } \\
\text { MW }\end{array}$ & Comments \\
\hline $\begin{array}{l}\text { Strobl and } \\
\text { Walsh (2003) }\end{array}$ & $\begin{array}{c}\text { Trinidad } \\
\text { and } \\
\text { Tobago }\end{array}$ & MW & $1996-$ & 294.3 males & 7 & $\begin{array}{l}\text { The authors study the effect of the implementation of the minimum } \\
\text { wage on bound vs. not bound workers, based on wages prior to the } \\
\text { minimum wage, by sex, for small and large firms. For each category, } \\
\text { they report the percent change in the wage bill if all workers are topped } \\
\text { up to the minimum wage, which we use to compute the percent change } \\
\text { in the wage for bound workers. And they report the raw baseline rate of } \\
\text { job loss for low-wage (bound) workers, by sex. We use these for both } \\
\text { small and large firms. Thus, the elasticity is calculated as the marginal } \\
\text { effect on job loss, multiplied by the ratio of the proportional change in } \\
\text { the wage bill divided by the rate of job loss. }\end{array}$ \\
\hline
\end{tabular}

Note: We are estimating the employment rate elasticities. For example, in Alaniz et al. (2011), the estimated effect of the log minimum wage on the probability of being employed is -0.31 for all workers. The paper reports an employment rate in the sample of 0.58 , so the elasticity of -0.53 results from dividing -0.31 by 0.58 . (See Appendix Table A2.) 
Appendix Table A2. Surveyed Studies, Estimated and Calculated Elasticities, and Classifications of Estimates (Authors' Preferred Estimates)

\begin{tabular}{|c|c|c|c|c|c|c|c|}
\hline Study & Country & Elasticity & Binding & Sector & Enforcement & Vulnerable & Comments \\
\hline \multirow[t]{3}{*}{ Alaniz et al. (2011) } & \multirow[t]{3}{*}{ Nicaragua } & $-0.898^{* * *}$ & Yes & Formal & Strong & Vulnerable & \multirow{3}{*}{$\begin{array}{l}\text { Coefficients are unique for the } \\
\text { categories. }\end{array}$} \\
\hline & & -0.834 & Yes & Formal & Strong & Vulnerable & \\
\hline & & $-0.533^{* * *}$ & Yes & Formal & Strong & All Workers & \\
\hline \multirow[t]{7}{*}{ Alatas and Cameron (2008) } & \multirow[t]{7}{*}{ Indonesia } & -0.20 & Yes & Informal & None & All Workers & \multirow[t]{7}{*}{ Different time periods. } \\
\hline & & $-0.459^{* * *}$ & Yes & Informal & None & All Workers & \\
\hline & & -0.016 & Yes & Informal & None & All Workers & \\
\hline & & $-0.16^{*}$ & Yes & Informal & None & All Workers & \\
\hline & & 0.037 & Yes & Formal & None & All Workers & \\
\hline & & 0.032 & Yes & Formal & None & All Workers & \\
\hline & & $-0.41^{*}$ & Yes & Informal & None & All Workers & \\
\hline \multirow[t]{2}{*}{ Arango and Pachón (2004) } & \multirow[t]{2}{*}{ Colombia } & $-0.407^{* *}$ & Yes & Both & Weak & All Workers & \multirow[t]{2}{*}{ Heads and non-heads of households. } \\
\hline & & $-1.205^{* * *}$ & Yes & Both & Weak & All Workers & \\
\hline \multirow{2}{*}{$\begin{array}{l}\text { Baranowska-Rataj and } \\
\text { Magda (2015) }\end{array}$} & \multirow[t]{2}{*}{ Poland } & $-0.186^{* * *}$ & N.d. & Formal & Strong & All Workers & Coefficients are unique for the \\
\hline & & $-0.365^{* * * *}$ & N.d. & Formal & Strong & Vulnerable & categories. \\
\hline Bell (1997) & Mexico & -0.027 & Yes & Formal & Weak & Vulnerable & Different econometric models: with \\
\hline & Colombia & -0.182 & No & Formal & None & All Workers & and without time fixed effects. \\
\hline & & $-0.337^{* * * *}$ & Yes & Formal & Weak & All Workers & \\
\hline & & $-0.033^{*}$ & Yes & Formal & Weak & Vulnerable & \\
\hline Bhorat et al. (2014) & South & $-0.130^{* * *}$ & Yes & Formal & Weak & All Workers & Different econometric models: with \\
\hline & Africa & -0.082 & Yes & Formal & Weak & All Workers & and without covariates. \\
\hline Broecke and Vandeweyer & Brazil & $-0.022^{* * *}$ & Yes & Both & Weak & All Workers & Different units: regions and \\
\hline$(2015)$ & & -0.014 & Yes & Both & Weak & Vulnerable & individuals. Different econometric \\
\hline & & -0.047 & Yes & Both & Weak & Vulnerable & models: with and without lags; \\
\hline & & -0.026 & Yes & Both & Weak & Vulnerable & different fixed effects. \\
\hline Carneiro (2004) & Brazil & $0.018^{* *}$ & N.d. & Informal & Weak & All Workers & Coefficients are unique for the \\
\hline & & -0.005 & N.d. & Formal & Weak & All Workers & categories \\
\hline Carneiro and Corseuil & Brazil & 2.097 & Yes & Formal & Weak & All Workers & Different time periods.. \\
\hline$(2001)$ & & -0.551 & Yes & Informal & Weak & All Workers & . \\
\hline & & 0 & Yes & Informal & Weak & All Workers & \\
\hline & & -2.530 & Yes & Formal & Weak & All Workers & \\
\hline & & 1.185 & Yes & Formal & Weak & All Workers & \\
\hline & & 0.718 & Yes & Informal & Weak & All Workers & \\
\hline & & 0 & Yes & Informal & Weak & All Workers & \\
\hline & & -0.055 & Yes & Formal & Weak & All Workers & \\
\hline & & -0.178 & Yes & Formal & Weak & All Workers & \\
\hline & & 0.754 & Yes & Informal & Weak & All Workers & \\
\hline Castillo-Freeman and & Puerto & $-0.54^{* * * *}$ & Yes & Formal & None & All Workers & Different time periods. . \\
\hline Freeman (1992) & Rico & $-0.91^{\text {**** }}$ & Yes & Formal & None & All Workers & \\
\hline Chun and Khor (2010) & Indonesia & $-0.112^{* *}$ & Yes & Formal & None & All Workers & Coefficients are unique for the \\
\hline & & -0.027 & Yes & Formal & None & Vulnerable & categories. \\
\hline Comola and Mello (2011) & Indonesia & $0.087^{* * *}$ & N.d. & Informal & None & All Workers & Different econometric methods of \\
\hline & & -0.053 & N.d. & Formal & None & All Workers & estimation: OLS and SUR. \\
\hline & & $0.082^{* * *}$ & N.d. & Informal & None & All Workers & \\
\hline & & $-0.052^{* * *}$ & N.d. & Formal & None & All Workers & \\
\hline & & $-0.028^{* * * *}$ & N.d. & Formal & None & Vulnerable & \\
\hline & & $0.027^{* * *}$ & N.d. & Informal & None & Vulnerable & \\
\hline Del Carpio et al. (2015) & Indonesia & $-0.069^{* * *}$ & Yes & Informal & None & Vulnerable & Different vulnerable groups: low- \\
\hline & & $-0.196^{* * *}$ & Yes & Informal & None & Vulnerable & education and female workers. \\
\hline & & $-0.034^{* *}$ & Yes & Formal & None & All Workers & \\
\hline & & $-0.026^{*}$ & Yes & Informal & None & All Workers & \\
\hline & & -0.043 & Yes & Informal & None & Vulnerable & \\
\hline Del Carpio et al. (2014) & Thailand & $-0.171^{* * *}$ & Yes & Formal & Strong & Vulnerable & Coefficients are unique for the \\
\hline & & $-0.078^{* *}$ & Yes & Both & Strong & All Workers & categories. \\
\hline & & -0.041 & Yes & Both & Strong & Vulnerable & \\
\hline & & -0.011 & Yes & Formal & Strong & All Workers & \\
\hline Dinkelman and Ranchhod & South & -0.138 & Yes & Formal & Weak & Vulnerable & Different econometric models: with \\
\hline (2012) & Africa & -0.192 & Yes & Formal & Weak & Vulnerable & and without covariates. \\
\hline Dung (2017) & Vietnam & $-0.527^{* *}$ & No & Both & None & All Workers & Different sectors. Type of workers: \\
\hline & & -0.157 & No & Both & None & All Workers & part-time and full-time. \\
\hline & & $-0.614^{* * * *}$ & No & Both & None & All Workers & \\
\hline & & $-0.216^{*}$ & No & Both & None & All Workers & \\
\hline Fajnzylber (2001) & Brazil & $-0.05^{* * *}$ & Yes & Informal & Weak & Vulnerable & Different econometric models: with \\
\hline & & $-0.08^{* * *}$ & Yes & Formal & Weak & Vulnerable & and without lags (formal): long-run \\
\hline & & $-0.05^{* * *}$ & Yes & Formal & Weak & Vulnerable & and short-run (informal). \\
\hline & & $-0.15^{* * *}$ & Yes & Informal & Weak & Vulnerable & \\
\hline & & $-0.10^{* * *}$ & Yes & Formal & Weak & Vulnerable & \\
\hline & & $-0.25^{* * *}$ & Yes & Informal & Weak & Vulnerable & \\
\hline & & $-0.35^{* * *}$ & Yes & Informal & Weak & Vulnerable & \\
\hline
\end{tabular}




\begin{tabular}{|c|c|c|c|c|c|c|c|}
\hline Study & Country & Elasticity & Binding & Sector & Enforcement & Vulnerable & Comments \\
\hline \multirow[t]{5}{*}{ Fang and Lin (2015) } & \multirow[t]{5}{*}{ China } & $-0.148^{* * *}$ & Yes & Formal & Strong & Vulnerable & \multirow{5}{*}{$\begin{array}{l}\text { Different vulnerable groups: } \\
\text { females, young adults, and low-wage } \\
\text { workers. }\end{array}$} \\
\hline & & $-0.213^{*}$ & Yes & Formal & Strong & Vulnerable & \\
\hline & & $-0.088^{* *}$ & Yes & Formal & Strong & Vulnerable & \\
\hline & & $-0.055^{* * *}$ & Yes & Formal & Strong & All Workers & \\
\hline & & -0.062 & Yes & Formal & Strong & Vulnerable & \\
\hline \multirow[t]{8}{*}{ Feliciano (1998) } & \multirow[t]{8}{*}{ Mexico } & $-0.406^{* *}$ & N.d. & Formal & None & Vulnerable & \multirow{8}{*}{$\begin{array}{l}\text { Different econometric models: with } \\
\text { and without covariates, and OLS or } \\
\text { IV. }\end{array}$} \\
\hline & & $-0.522^{* * *}$ & N.d. & Formal & None & Vulnerable & \\
\hline & & $-1.107^{* * *}$ & N.d. & Formal & None & Vulnerable & \\
\hline & & -0.074 & N.d. & Formal & None & All Workers & \\
\hline & & 0.005 & N.d. & Formal & None & All Workers & \\
\hline & & 0.014 & N.d. & Formal & None & All Workers & \\
\hline & & $-0.426^{* * *}$ & N.d. & Formal & None & Vulnerable & \\
\hline & & $-1.13^{* *}$ & N.d. & Formal & None & Vulnerable & \\
\hline \multirow[t]{2}{*}{ Foguel (1998) } & \multirow[t]{2}{*}{ Brazil } & $-0.135^{* * *}$ & N.d. & Both & Weak & All Workers & \multirow{2}{*}{$\begin{array}{l}\text { Coefficients are unique for the } \\
\text { categories. }\end{array}$} \\
\hline & & $0.60^{* * * *}$ & N.d. & Informal & Weak & All Workers & \\
\hline \multirow[t]{2}{*}{ Foguel et al. (2001) } & \multirow[t]{2}{*}{ Brazil } & 0.018 & N.d. & Informal & Weak & All Workers & Coefficients are unique for the \\
\hline & & $-0.011^{*}$ & N.d. & Formal & Weak & All Workers & categories. \\
\hline Garza Cantú and Bazaldúa & Mexico & $0.754^{* * *}$ & N.d. & Formal & None & Vulnerable & Coefficients are unique for the \\
\hline (2002) & & $-0.204^{* *}$ & N.d. & Formal & None & All Workers & categories. \\
\hline Gindling and Terrell (2007) & $\begin{array}{l}\text { Costa } \\
\text { Rica }\end{array}$ & $-0.109^{*}$ & Yes & Formal & Weak & All Workers & $\begin{array}{l}\text { Coefficients are unique for the } \\
\text { categories. }\end{array}$ \\
\hline Gindling and Terrell (2008) & Honduras & $-0.458^{* * *}$ & Yes & Formal & Weak & All Workers & Large and small firms. \\
\hline & & $0.392^{*}$ & Yes & Formal & Weak & All Workers & \\
\hline Grau and Landerretche & Chile & $-0.312^{* * *}$ & Yes & Both & Strong & Vulnerable & Different interactions. \\
\hline (2011) & & $-0.339^{* * *}$ & Yes & Both & Strong & Vulnerable & \\
\hline Ham (2018) & Honduras & $-0.471 * * *$ & Yes & Formal & Weak & All Workers & Different econometric models: probit \\
\hline & & $0.276^{* * *}$ & Yes & Informal & Weak & All Workers & and multinomial logit \\
\hline & & $0.34 * * *$ & Yes & Informal & Weak & All Workers & \\
\hline & & $-0.088^{* * * *}$ & Yes & Both & Weak & All Workers & \\
\hline & & $-0.111 * * *$ & Yes & Both & Weak & All Workers & \\
\hline & & $-0.383 * * *$ & Yes & Formal & Weak & All Workers & \\
\hline Harrison and Scorse (2010) & Indonesia & $-0.125^{* * *}$ & Yes & Both & None & All Workers & Different sectors: one excludes \\
\hline & & $-0.116^{* * *}$ & Yes & Formal & None & All Workers & textiles. \\
\hline & & $-0.123^{* * *}$ & Yes & Both & None & All Workers & \\
\hline Hernandez Diaz and Pinzon & Colombia & -0.245 & Yes & Formal & Weak & Vulnerable & Coefficients are unique for the \\
\hline Garcia (2006) & & -0.207 & Yes & Formal & Weak & All Workers & categories. \\
\hline Hernandez and Lasso (2003) & Colombia & 0.154 & N.d. & Both & Weak & Vulnerable & Different vulnerable groups: young \\
\hline & & -0.219 & N.d. & Both & Weak & All Workers & and low-skilled workers. \\
\hline & & 0.005 & N.d. & Both & Weak & Vulnerable & \\
\hline Hertz (2005) & South & -0.33 & Yes & Formal & Weak & All Workers & Coefficients are unique for the \\
\hline & Africa & -0.46 & Yes & Formal & Weak & Vulnerable & categories. \\
\hline Hohberg and Lay (2015) & Indonesia & $-0.074^{* * *}$ & No & Informal & None & All Workers & Coefficients are unique for the \\
\hline & & $0.090^{* * *}$ & Yes & Formal & None & All Workers & categories. \\
\hline Huang et al. (2014) & China & $-0.033^{* * *}$ & Yes & Formal & Strong & All Workers & Different regions. \\
\hline & & $-0.017^{* * *}$ & Yes & Formal & Strong & All Workers & \\
\hline & & $0.058^{* * *}$ & Yes & Informal & Strong & All Workers & \\
\hline & & $-0.017^{* * *}$ & Yes & Formal & Strong & All Workers & \\
\hline Islam and Nazara (2000) & Indonesia & $-0.059^{* * *}$ & N.d. & Formal & None & All Workers & $\begin{array}{l}\text { Coefficients are unique for the } \\
\text { categories. }\end{array}$ \\
\hline Kamińska and & Poland & -0.027 & Yes & Formal & Strong & Vulnerable & Different vulnerable groups: young \\
\hline Lewandowski (2015) & & -0.005 & Yes & Formal & Strong & Vulnerable & and low-wage workers divided in: \\
\hline & & $-0.016^{* * *}$ & Yes & Formal & Strong & Vulnerable & full-time and part-time, and \\
\hline & & -0.010 & Yes & Formal & Strong & Vulnerable & temporary and permanent workers. \\
\hline & & $-0.06^{* * *}$ & Yes & Formal & Strong & Vulnerable & \\
\hline & & $-0.101^{* * *}$ & Yes & Formal & Strong & Vulnerable & \\
\hline & & $-0.049^{* * *}$ & Yes & Formal & Strong & Vulnerable & \\
\hline Lemos (2004a) & Brazil & 0.004 & Yes & Formal & Weak & All Workers & Different econometric models: \\
\hline & & 0.003 & Yes & Formal & Weak & All Workers & dynamic and with covariates. \\
\hline & & -0.038 & Yes & Formal & Weak & All Workers & \\
\hline Lemos (2004b) & Brazil & -0.001 & Yes & Both & Weak & All Workers & $\begin{array}{l}\text { Coefficients are unique for the } \\
\text { categories. }\end{array}$ \\
\hline Lemos $(2004 \mathrm{c})$ & Brazil & -0.001 & Yes & Formal & Weak & All Workers & Different econometric models: with \\
\hline & & 0.010 & Yes & Informal & Weak & All Workers & and without lags of employment. \\
\hline & & $-0.017^{* * *}$ & Yes & Informal & Weak & All Workers & \\
\hline & & $-0.004^{* *}$ & Yes & Formal & Weak & All Workers & \\
\hline Lemos (2005a) & Brazil & 0.012 & Yes & Both & Weak & Vulnerable & Different econometric models and \\
\hline & & -0.009 & Yes & Informal & Weak & All Workers & different estimation methods: with \\
\hline & & 0.002 & Yes & Formal & Weak & All Workers & and without lags; OLS and IV. \\
\hline & & -0.003 & Yes & Formal & Weak & All Workers & \\
\hline & & -0.005 & Yes & Both & Weak & Vulnerable & \\
\hline & & -0.003 & Yes & Formal & Weak & All Workers & \\
\hline
\end{tabular}




\begin{tabular}{|c|c|c|c|c|c|c|c|}
\hline Study & Country & Elasticity & Binding & Sector & Enforcement & Vulnerable & Comments \\
\hline & & -0.029 & Yes & Formal & Weak & All Workers & \\
\hline & & -0.004 & Yes & Formal & Weak & All Workers & \\
\hline & & -0.002 & Yes & Formal & Weak & All Workers & \\
\hline & & -0.021 & Yes & Informal & Weak & All Workers & \\
\hline & & -0.003 & Yes & Formal & Weak & All Workers & \\
\hline Lemos (2005b) & Brazil & $-0.005^{*}$ & Yes & Both & Weak & All Workers & $\begin{array}{l}\text { Coefficients are unique for the } \\
\text { categories }\end{array}$ \\
\hline \multirow[t]{4}{*}{ Lemos (2007) } & \multirow[t]{4}{*}{ Brazil } & 0.002 & Yes & Both & Weak & Vulnerable & \multirow{4}{*}{$\begin{array}{l}\text { Different econometric models all } \\
\text { workers: lags and no lags. Different } \\
\text { vulnerable groups: young adults and } \\
\text { female workers. }\end{array}$} \\
\hline & & -0.001 & Yes & Both & Weak & All Workers & \\
\hline & & 0.002 & Yes & Both & Weak & Vulnerable & \\
\hline & & 0.003 & Yes & Both & Weak & All Workers & \\
\hline \multirow[t]{5}{*}{ Lemos (2009a) } & \multirow[t]{5}{*}{ Brazil } & -0.062 & Yes & Formal & Weak & All Workers & \multirow{5}{*}{$\begin{array}{l}\text { Different models: lags and no lags; } \\
\text { with covariates and without } \\
\text { covariates. }\end{array}$} \\
\hline & & 0.026 & Yes & Informal & Weak & All Workers & \\
\hline & & $0.177^{*}$ & Yes & Informal & Weak & All Workers & \\
\hline & & $-0.126^{*}$ & Yes & Formal & Weak & All Workers & \\
\hline & & 0.147 & Yes & Informal & Weak & All Workers & \\
\hline \multirow[t]{3}{*}{ Lemos (2009b) } & \multirow[t]{3}{*}{ Brazil } & $-0.045^{* * *}$ & Yes & Both & Weak & Vulnerable & \multirow{3}{*}{$\begin{array}{l}\text { Different vulnerable groups: young } \\
\text { adults and the affected fraction of } \\
\text { workers (based on low wages). }\end{array}$} \\
\hline & & -0.096 & Yes & Both & Weak & Vulnerable & \\
\hline & & -0.073 & Yes & Both & Weak & All Workers & \\
\hline \multirow[t]{3}{*}{ Luo et al. (2011) } & China & $0.109^{* * *}$ & N.d. & Formal & Strong & All Workers & Different sectors: manufacturing, \\
\hline & & $-0.236^{* * *}$ & N.d. & Formal & Strong & All Workers & construction, and wholesale. \\
\hline & & $0.134^{* * *}$ & N.d. & Formal & Strong & All Workers & \\
\hline Magruder (2013) & Indonesia & $-0.218^{* * *}$ & Yes & Informal & None & All Workers & Different type of workers: full-time \\
\hline & & $-0.090^{* * *}$ & Yes & Informal & None & All Workers & and self-employed. Different \\
\hline & & $0.104^{* *}$ & Yes & Formal & None & All Workers & distance in difference-in-differences \\
\hline & & $0.127^{* * *}$ & Yes & Formal & None & All Workers & estimates: 15 and 30 miles. \\
\hline Majchrowska and & Polonia & $-0.08^{* * * *}$ & N.d. & Formal & Strong & All Workers & Different econometric models: \\
\hline Zółkiewski (2012) & & $-0.10^{* * * *}$ & N.d. & Formal & Strong & All Workers & Arellano-Bond and Blundell-Bond. \\
\hline & & $-0.27^{*}$ & N.d. & Formal & Strong & Vulnerable & Different time periods. \\
\hline & & $-0.50^{* * * *}$ & N.d. & Formal & Strong & Vulnerable & \\
\hline & & -0.47 & N.d. & Formal & Strong & Vulnerable & \\
\hline Maloney and Nuñez & Colombia & $-0.524^{* * *}$ & Yes & Formal & Weak & Vulnerable & Workers with different levels of \\
\hline Mendez (2004) & & $-0.345^{* * *}$ & Yes & Formal & Weak & Vulnerable & income: Workers earning between 0 \\
\hline & & $-0.432^{* * * *}$ & Yes & Informal & Weak & Vulnerable & and $0.5 \mathrm{MW}, 0$ and $0.7 \mathrm{MW}$ and 0.7 , \\
\hline & & $-0.15^{* * *}$ & Yes & Formal & Weak & All Workers & and $0.9 \mathrm{MW}$. \\
\hline & & $-0.367^{* * *}$ & Yes & Informal & Weak & Vulnerable & \\
\hline & & $-0.205^{* * *}$ & Yes & Informal & Weak & Vulnerable & \\
\hline & & $-0.683^{* * *}$ & Yes & Formal & Weak & Vulnerable & \\
\hline Martinez et al. (2001) & Chile & -0.01 & N.d. & Formal & Strong & All Workers & Different econometric methods: OLS \\
\hline & & 0.04 & N.d. & Formal & Strong & All Workers & $\begin{array}{l}\text { and Stock-Watson. Different } \\
\text { periods. }\end{array}$ \\
\hline Mayneris et al. (2014) & China & -0.045 & Yes & Formal & Strong & All Workers & Different regions: with and without \\
\hline & & 0.162 & Yes & Formal & Strong & All Workers & the periphery. \\
\hline Menon and Meulen Rodgers & India & -1.996 & No & Both & None & Vulnerable & Different regions: rural and urban. \\
\hline (2017) & & $0.792^{* * *}$ & Yes & Formal & None & All Workers & Different sectors: all industries and \\
\hline & & $0.767^{* * * *}$ & Yes & Both & None & All Workers & other industries. \\
\hline & & 0.175 & No & Both & None & All Workers & \\
\hline & & $-2.231^{* * *}$ & Yes & Informal & None & Vulnerable & \\
\hline & & 0.051 & Yes & Informal & None & All Workers & \\
\hline & & $1.793^{* * *}$ & Yes & Both & None & Vulnerable & \\
\hline & & $2.073^{* * *}$ & Yes & Formal & None & Vulnerable & \\
\hline & & -0.067 & Yes & Formal & None & All Workers & \\
\hline & & $-0.787^{* * *}$ & Yes & Informal & None & All Workers & \\
\hline & & 2.194 & Yes & Formal & None & Vulnerable & \\
\hline & & -2.183 & Yes & Informal & None & Vulnerable & \\
\hline Miranda (2013) & Chile & $-0.36^{* * *}$ & N.d. & Formal & Strong & All Workers & Different sectors: all goods and only \\
\hline & & $-0.28^{* * *}$ & N.d. & Formal & Strong & All Workers & "tradable" goods. \\
\hline Montenegro and Pagés & Chile & $0.140^{* * *}$ & N.d. & Formal & Strong & Vulnerable & Different vulnerable groups: female \\
\hline (2004) & & $0.095^{* * *}$ & N.d. & Formal & Strong & Vulnerable & and young workers. \\
\hline Neumark et al. (2006) & Brazil & 0.068 & Yes & Formal & Weak & All Workers & Coefficients are unique for the \\
\hline & & -0.012 & Yes & Formal & Weak & Vulnerable & categories. \\
\hline Ni et al (2011) & China & -0.032 & N.d. & Formal & Strong & Vulnerable & Coefficients are unique for the \\
\hline & & 0.098 & N.d. & Formal & Strong & All Workers & categories. \\
\hline Papps (2012) & Turkey & 0.004 & Yes & Formal & Weak & All Workers & Coefficients are unique for the \\
\hline & & 0.001 & Yes & Formal & Weak & All Workers & categories. \\
\hline & & -0.002 & Yes & Informal & Weak & All Workers & \\
\hline Pelek (2011) & Turkey & 0.182 & Yes & Informal & Weak & All Workers & Different measurements of the \\
\hline & & 0.008 & Yes & Formal & Weak & Vulnerable & minimum wage: Kaitz index, real, \\
\hline & & $0.149^{* * *}$ & Yes & Informal & Weak & All Workers & and fraction between 0.95 and 1.05 \\
\hline & & 0.022 & Yes & Formal & Weak & Vulnerable & times the minimum wage. \\
\hline & & 0.024 & Yes & Formal & Weak & Vulnerable & \\
\hline
\end{tabular}




\begin{tabular}{|c|c|c|c|c|c|c|c|}
\hline Study & Country & Elasticity & Binding & Sector & Enforcement & Vulnerable & Comments \\
\hline & & -0.029 & Yes & Informal & Weak & All Workers & \\
\hline & & 0.008 & Yes & Formal & Weak & All Workers & \\
\hline & & 0.024 & Yes & Formal & Weak & All Workers & \\
\hline \multirow[t]{2}{*}{ Shi (2011) } & \multirow[t]{2}{*}{ China } & $-0.587^{* * *}$ & N.d. & Formal & Strong & All Workers & \multirow{2}{*}{$\begin{array}{l}\text { Different sectors: construction and } \\
\text { manufacturing. }\end{array}$} \\
\hline & & -0.128 & N.d. & Formal & Strong & All Workers & \\
\hline \multirow[t]{4}{*}{ Strobl and Walsh (2003) } & \multirow[t]{4}{*}{ Trinidad } & $-0.048^{* * *}$ & Yes & Both & Strong & All Workers & \multirow[t]{4}{*}{ Different firm sizes. } \\
\hline & & $-0.151^{*}$ & Yes & Both & Strong & Vulnerable & \\
\hline & & -0.016 & Yes & Both & Strong & Vulnerable & \\
\hline & & $-0.036^{*}$ & Yes & Both & Strong & All Workers & \\
\hline \multirow[t]{3}{*}{ Suryahadi et al. (2003) } & \multirow[t]{3}{*}{ Indonesia } & $-0.112^{* * * *}$ & Yes & Formal & None & All Workers & \multirow{3}{*}{$\begin{array}{l}\text { Different vulnerable groups: female } \\
\text { and young workers. }\end{array}$} \\
\hline & & $-0.307^{* * *}$ & Yes & Formal & None & Vulnerable & \\
\hline & & $-0.307^{* * *}$ & Yes & Formal & None & Vulnerable & \\
\hline \multirow{7}{*}{$\begin{array}{l}\text { Wang and Gunderson } \\
\text { (2011) }\end{array}$} & \multirow[t]{7}{*}{ China } & $-1.042^{* *}$ & N.d. & Formal & Strong & All Workers & \multirow{7}{*}{$\begin{array}{l}\text { Different regions. Different types of } \\
\text { firms: state-owned and private. }\end{array}$} \\
\hline & & -0.202 & N.d. & Formal & Strong & All Workers & \\
\hline & & -0.156 & N.d. & Formal & Strong & All Workers & \\
\hline & & $0.356^{*}$ & N.d. & Formal & Strong & All Workers & \\
\hline & & -0.178 & N.d. & Formal & Strong & All Workers & \\
\hline & & -0.225 & N.d. & Formal & Strong & All Workers & \\
\hline & & 0.166 & N.d. & Formal & Strong & All Workers & \\
\hline \multirow{3}{*}{$\begin{array}{l}\text { Wang and Gunderson } \\
\text { (2012) }\end{array}$} & \multirow[t]{3}{*}{ China } & -0.510 & No & Formal & Strong & Vulnerable & \multirow{3}{*}{$\begin{array}{l}\text { Effects for different sectors of the } \\
\text { economy like construction, retail, } \\
\text { etc. }\end{array}$} \\
\hline & & 0.430 & No & Formal & Strong & All Workers & \\
\hline & & -0.150 & No & Formal & Strong & All Workers & \\
\hline \multirow[t]{2}{*}{ Xiao and Xiang (2009) } & \multirow[t]{2}{*}{ China } & $-0.022^{* *}$ & Yes & Both & Strong & All Workers & \multirow{2}{*}{$\begin{array}{l}\text { Different estimation methods: } \\
\text { difference-in-differences and levels. }\end{array}$} \\
\hline & & $-0.001^{* * *}$ & Yes & Both & Strong & All Workers & \\
\hline
\end{tabular}

${ }^{* * * *} \mathrm{p}<0.01,{ }^{* * *} \mathrm{p}<0.05,{ }^{*} \mathrm{p}<0.1$.

Notes: Vulnerable workers are young adults, less-skilled workers, female workers, or workers earning very close to the minimum wage. Informal sector includes small firms for the case of Indonesia (as suggested in some papers). Binding is defined based on evidence of positive wage effects. Most analyses are for the formal section, while some papers report results for the informal sector or the two sectors combined. Enforcement is defined by penalties in the law, following Munguía Corella (2019). For studies for which we had to compute elasticities, we use the statistical significance of the reported employment effect. For Neumark et al. (2006), the estimate for household heads is classified as for all workers, and the estimate excluding the household head is classified as for vulnerable workers. For Strobl and Walsh (2003), the estimated elasticity for small firms, for men, is statistically significant. They also report a significant coefficient estimate for the interaction of the minimum wage variable with an indicator for large firms, for women. However, this estimate is not statistically significant, and we have no way of assessing the significance of the overall effect of the minimum wage for women working at large firms (which is this interaction plus the estimated minimum wage effect), so we do not code this estimate as statistically significant. 
Appendix Table A3. Classification of Studies by Country and Bindingness

\begin{tabular}{|l|c|c|c|c|}
\hline \multicolumn{1}{|c|}{ Country } & $\begin{array}{c}\text { Number of } \\
\text { studies }\end{array}$ & Binding & Not binding & No data \\
\hline Brazil & 15 & 12 & 0 & 3 \\
\hline Chile & 4 & 1 & 0 & 3 \\
\hline China & 9 & 4 & 1 & 4 \\
\hline Colombia & 5 & 4 & 0 & 1 \\
\hline Costa Rica & 1 & 1 & 0 & 0 \\
\hline Honduras & 2 & 2 & 0 & 0 \\
\hline India & 1 & 0.8 & 0.2 & 0 \\
\hline Indonesia & 9 & 6.5 & 0.5 & 2 \\
\hline Mexico & 3 & 0 & 1 & 2 \\
\hline Nicaragua & 1 & 1 & 0 & 0 \\
\hline Poland & 3 & 1 & 0 & 2 \\
\hline Puerto Rico & 1 & 1 & 0 & 0 \\
\hline South Africa & 3 & 3 & 0 & 0 \\
\hline Thailand & 1 & 1 & 0 & 0 \\
\hline Trinidad & 1 & 1 & 0 & 0 \\
\hline Turkey & 2 & 2 & 0 & 0 \\
\hline Vietnam & 1 & 0 & 1 & 0 \\
\hline
\end{tabular}

Notes: In the second through fourth columns, we average the number of results by study, and then we sum by country. The non-integers result when there is variation in bindingness across estimates in a study. For India (Menon and Meulen Rodgers, 2017), the minimum wage is non-binding in the urban areas, but it is binding in the rural areas. For Indonesia (Hohberg and Lay, 2015), the minimum wage is non-binding for the informal sector and binding for the formal sector. 
Appendix Table A4. Numbers of Estimates for Sets of Estimate Covered in Figures 2A-3B

\begin{tabular}{|c|c|c|c|c|c|}
\hline Two estimate features & $\begin{array}{c}\text { Number } \\
\text { of } \\
\text { estimates }\end{array}$ & Three estimate features & $\begin{array}{c}\text { Number } \\
\text { of } \\
\text { estimates }\end{array}$ & Four estimate features & $\begin{array}{c}\text { Number } \\
\text { of } \\
\text { estimates }\end{array}$ \\
\hline Both predict stronger negative effects & & All predict stronger negative effects & & All predict stronger negative effects & \\
\hline Formal/Binding & 91 & Binding/Formal/Strong & 22 & Binding/Formal/Strong/Vulnerable & 14 \\
\hline Strong/Binding & 33 & Binding/Formal/Vulnerable & 35 & None predict stronger negative effects & \\
\hline Vulnerable/Binding & 62 & Binding/Strong/Vulnerable & 19 & Informal/Weak/Non-binding/All Workers & 0 \\
\hline Strong/Formal & 52 & Formal/Strong/Vulnerable & 22 & Informal/Weak/No data (binding)/All Workers & 3 \\
\hline Vulnerable/Formal & 50 & None predict stronger negative effects & & Informal/None/Non-binding/All Workers & 1 \\
\hline Vulnerable/Strong & 27 & Informal/Weak/Non-binding & 0 & Informal/None/No data (binding)/All Workers & 2 \\
\hline One predicts stronger negative effects & & Informal/Weak/No data (binding) & 3 & Both/Weak/Non-binding/All Workers & 0 \\
\hline Binding/Informal & 41 & Informal/Weak/All Workers & 21 & Both/Weak/No data (binding)/All Workers & 2 \\
\hline Binding/Both & 33 & Informal/None/Non-binding & 1 & Both/None/Non-binding/All Workers & 5 \\
\hline Binding/Weak & 95 & Informal/None/No data (binding) & 3 & Both/None/No data (binding)/All Workers & 0 \\
\hline Binding/None & 37 & Informal/None/All Workers & 13 & & \\
\hline Binding/All Workers & 103 & Informal/Non-binding/All Workers & 1 & & \\
\hline Formal/Weak & 53 & Informal/No data (binding)/All Workers & 5 & & \\
\hline Formal/None & 37 & Both/Weak/Non-binding & 0 & & \\
\hline Formal/Non-binding & 4 & Both/Weak/No data (binding) & 4 & & \\
\hline Formal/No data (binding) & 43 & Both/Weak/All Workers & 12 & & \\
\hline Strong/All Workers & 36 & Both/None/Non-binding & 6 & & \\
\hline Strong/Non-binding & 3 & Both/None/No data (binding) & 0 & & \\
\hline Strong/No data (binding) & 27 & Both/None/All Workers & 8 & & \\
\hline Strong/Informal & 1 & Both/Non-binding/All Workers & 5 & & \\
\hline Strong/Both & 8 & Both/No data (binding)/All Workers & 2 & & \\
\hline Vulnerable/Non-binding & 2 & None/Non-binding/All Workers & 7 & & \\
\hline Vulnerable/No data (binding) & 17 & None/No data (binding)/All Workers & 9 & & \\
\hline Vulnerable/Informal & 13 & Weak/Non-binding/All Workers & 0 & & \\
\hline Vulnerable/Both & 7 & Weak/No data (binding)/All Workers & 7 & & \\
\hline Vulnerable/Weak & 34 & Informal/Weak/Non-binding & 0 & & \\
\hline Vulnerable/None & 34 & Informal/Weak/No data (binding) & 3 & & \\
\hline Neither predicts stronger negative effects & & Informal/Weak/All Workers & 21 & & \\
\hline Non-binding/Informal & 1 & Informal/None/Non-binding & 1 & & \\
\hline Non-binding/Both & 6 & Informal/None/No data (binding) & 3 & & \\
\hline Non-binding/Weak & 0 & Informal/None/All Workers & 13 & & \\
\hline Non-binding/None & 8 & Informal/Non-binding/All Workers & 1 & & \\
\hline Non-binding/All Workers & 9 & Informal/No data (binding)/All Workers & 5 & & \\
\hline Informal/Weak & 28 & Both/Weak/Non-binding & 0 & & \\
\hline Informal/None & 19 & Both/Weak/No data (binding) & 4 & & \\
\hline Informal/All Workers & 6 & Both/Weak/All Workers & 12 & & \\
\hline Informal/No data (binding) & 35 & Both/None/Non-binding & 6 & & \\
\hline Weak/All Workers & 70 & & & & \\
\hline Weak/No data (binding) & 9 & & & & \\
\hline Weak/Both & 12 & & & & \\
\hline All Workers/Both & 22 & & & & \\
\hline All Workers/None & 74 & & & & \\
\hline All Workers/No data (binding) & 0 & & & & \\
\hline None/No data (binding) & 17 & & & & \\
\hline None/Both & 4 & & & & \\
\hline Both/No data (binding) & 35 & & & & \\
\hline
\end{tabular}

Note: As explained in the text, the classifications here pertain to the listed features of estimates. Thus, for example, under "two estimate features, both predict stronger negative effects," the two listed features more strongly predict negative effects and the other features are unspecified, so in actual fact in some cases three or four features of estimates may more strongly predict negative effects. 
Appendix Table A5. Meta-Analysis Regressions, Based on Counts of Features of Estimates More Strongly Predicting Negative Employment Effects (Excluding Brazil)

\begin{tabular}{|l|c|c|c|}
\hline & $(1)$ & $(2)$ & $(3)$ \\
\hline $\begin{array}{l}\text { Variables: number of features of estimates that } \\
\text { more strongly predict negative employment } \\
\text { effects }\end{array}$ & $\begin{array}{c}\text { Negative estimate } \\
(\mathrm{LPM})\end{array}$ & $\begin{array}{c}\text { Negative and } \\
\text { significant estimate } \\
(\mathrm{LPM})\end{array}$ & $\begin{array}{c}\text { Estimated } \\
\text { elasticity }\end{array}$ \\
\hline & & & -0.163 \\
\hline No estimate features & $0.667^{* * *}$ & $0.333^{* *}$ & $(0.120)$ \\
\hline & $(0.234)$ & $(0.142)$ & $-0.146^{* *}$ \\
\hline One estimate feature & $0.686^{* * *}$ & $0.371^{* * *}$ & $(0.072)$ \\
\hline & $(0.090)$ & $(0.094)$ & 0.910 \\
\hline One = No (p-value) & 0.939 & 0.813 & $-0.173^{* * *}$ \\
\hline Two estimate features & $0.708^{* * *}$ & $0.500^{* * *}$ & $(0.052)$ \\
\hline & $(0.064)$ & $(0.083)$ & 0.761 \\
\hline Two = One (p-value) & 0.854 & 0.320 & 0.939 \\
\hline Two = No (p-value) & 0.865 & 0.321 & -0.060 \\
\hline Three study features & $0.789 * * *$ & $0.368^{* * *}$ & $(0.131)$ \\
\hline & $(0.099)$ & $(0.112)$ & 0.463 \\
\hline Three = Two (p-value) & 0.416 & 0.288 & 0.633 \\
\hline Three = One (p-value) & 0.345 & 0.982 & 0.500 \\
\hline Three = No (p-value) & 0.613 & 0.84 & -0.192 \\
\hline Four estimate features & 1.000 & $0.571^{* * *}$ & $(0.127)$ \\
\hline & $(0.000)$ & $(0.039)$ & 0.459 \\
\hline Four = Three (p-value) & 0.039 & 0.120 & 0.892 \\
\hline Four = Two (p-value) & 0 & 0.430 & 0.755 \\
\hline Four = One (p-value) & 0.001 & 0.055 & 0.869 \\
\hline Four = No (p-value) & 0.161 & 0.113 & 0.912 \\
\hline Joint test: Four = Three = Two = One (p-value) & 0 & 0.205 & 168 \\
\hline Observations & 168 & 168 & \\
\hline
\end{tabular}

${ }^{* * *} \mathrm{p}<0.01,{ }^{* *} \mathrm{p}<0.05,{ }^{*} \mathrm{p}<0.1$.

Note: $\mathrm{LPM}=$ linear probability model. The variables are defined to be mutually exclusive. There are 168 observations and 46 clusters. For the LPMs, standard errors are clustered by study. Note that for the estimates in column (1), there is no variation in the dependent variable for the "Four estimate features" variables, which is why there is no variation in the estimated coefficient. The only difference relative to Table 3 is the exclusion of studies for Brazil. 


\section{Endnotes}

${ }^{1}$ For a recent review of the U.S. evidence, including discussion of the conflicting evidence and which methods point to disemployment effects, see Neumark (2019).

${ }^{2}$ For evidence on this question from over a decade ago, see Neumark et al. (2006) and Cunningham (2007).

${ }^{3}$ Still, the monopsony model makes more direct predictions than simply that employment effects are heterogeneous, and it would be important to test these predictions. For related work for the United States, see Azar et al. (2009) and Munguía Corella (forthcoming).

${ }^{4}$ See Wolfson and Belman (2019) for more discussion about different types and uses of meta-analysis in general, and in the minimum wage literature.

${ }^{5}$ See Neumark (2016) for discussion of some of these meta-analyses of estimated minimum wage effects in the United States, especially with reference to testing for publication bias. In a nutshell, it is hard to distinguish between publication bias and other sources of patterns in the published evidence consistent with publication bias. For example, meta-analyses like Doucouliagos and Stanley (2009) argue that if published negative estimates of minimum wage effects have larger standard errors, this is evidence of publication bias. However, the same phenomenon can arise if studies using better research designs lead to "truer" (i.e., less biased) estimates, which happen to be negative, and which have larger standard errors because they demand more of the data.

${ }^{6}$ We define developing countries as those that the World Bank does not classify as a high-income country. Poland became a high-income country in 2009, but the data in the papers on Poland cover predominantly earlier data (1999 to 2011 in all papers except one that extends to 2013).

${ }^{7}$ We also added one paper published in this journal (Ham, 2018) that did not appear in our search but was identified by a reviewer.

${ }^{8}$ The only exceptions were four earlier, often-cited papers that appear in more than one meta-analysis: Bell (1997) for Mexico; Castillo-Freeman and Freeman (1992) for Puerto Rico; and Feliciano (1998) and 
Foguel (1998) for Brazil. Appendix Figure A1 shows the distribution of these studies by year (publication date). The figure shows that the plurality of these studies were published in this decade and most in the last two decades. Of course papers studying minimum wages in developing countries continue to be produced and published (e.g., Asmal et al. (2019), but we had to cut off the sample period for analysis for this version of our paper.

${ }^{9}$ Below, we discuss the studies we include and the elasticity calculations in more detail, and Appendix Table A2 lists all the studies and the elasticities.

${ }^{10} \mathrm{We}$ are not arguing that this is necessarily the preferred approach for interpreting a broad literature. Indeed, in the U.S. context, Neumark and Wascher (2007) offer reasons why a narrative review (with some emphasis on what appear to be more credible estimates) may be preferred. On the other hand, they also argue that a narrative review may be more effective at highlighting some of the reasons for differences across studies attributable to the groups studied or other theoretical predictions. The present paper adopts the latter perspective to some extent - focusing on explaining differences in results across studies, albeit without discarding estimates.

${ }^{11}$ An example of the latter is Mayneris et al. (2014), who report both OLS and IV estimates, but take a clear stance that there may be endogeneity bias in their approach that requires instrumenting for the minimum wage variable.

${ }^{12}$ For studies for which we had to compute elasticities, we use the statistical significance of the reported employment effect.

${ }^{13}$ We do not do this trimming in any of the figures or estimates that follow, where we use all the elasticities preferred by the authors, even if the elasticity appears to be an extreme value.

${ }^{14}$ There are no studies that report the fraction affected but not the evidence on bindingness that we use, and all of the studies that do report a positive fraction affected also show a positive effect on wages. Thus, we would not classify additional studies by using the fraction affected.

${ }^{15}$ It is possible that there is a "file-drawer" problem (e.g., Franco et al., 2014), such that studies that do not detect, in initial analyses, an effect of the minimum wage on wages of low-wage workers are not 
pursued further, because of the strong expectation that - whatever the effects on employment - minimum wages should push up wages at the bottom of the wage distribution. This may constrain our ability to garner evidence on how the employment effects of minimum wages estimated in different studies vary with whether or not the minimum wage is binding.

${ }^{16}$ Alternatively, lighthouse effects could reflect a reference price, a signal for bargaining, or the impact of fairness concerns - all influences on wages outside of the usual competitive model. See the discussion and related references in Boeri et al. (2011).

${ }^{17}$ See http://www.ilo.org/dyn/natlex/natlex4.home?p_lang=en.

${ }^{18}$ Clemens and Strain (2020) find evidence of this in the U.S. context, reporting that subminimum wage payments when minimum wages increase rise the most in states with relatively strong minimum wage enforcement. Because minimum wage violations in the United States are driven by worker complaints, they interpret this as workers "enforcing less" when the higher minimum wage is more likely to cost jobs. ${ }^{19}$ The conclusions were very similar using a $10 \%$ significance level, because very few estimates are significant at the $10 \%$ level but not the $5 \%$ level.

${ }^{20}$ This same pattern of variation is often observed within studies. In Appendix Table A2 see, for example, Baranowska-Rataj and Magda (2015), Feliciano (1998), and Maloney and Nuñez (2004).

${ }^{21}$ However, we created a version of Table 2 in which we broke out the insignificant negative and the insignificant positive estimates. There was not much systematic difference across the different types of estimates; in other words, the differences associated with whether the estimate is negative and significant are more pronounced. (Results available upon request.) However, in the more-refined analyses that follow, we look at estimates distinguished in this way.

${ }^{22}$ There is one case - "Strong/Informal" - where "all" the estimates are positive and significant. But Appendix Table A4 shows that there is only one elasticity in this category.

${ }^{23}$ Following what we did before, we report results for each combination of three features of estimates that more strongly predict negative employment effects, without specifying the fourth feature - which hence may or may not more strongly predict negative effects. 
${ }^{24}$ One might be concerned that the evidence for Brazil drives the results because we have 15 studies for this country (see Appendix Table A3). However, the estimates are very similar excluding the studies of Brazil (Appendix Table A5).

${ }^{25}$ The estimates in column (12) provide a nice illustration of why the evidence from the columns for whether there is a negative estimated effect or a negative and significant estimated effect can be more reliable than the evidence for the estimated elasticity, as the latter can be sensitive to outliers. For the estimates for studies with one feature that more strongly predicts negative employment effects, the coefficients in columns (10) and (11) are larger for the studies that do not focus on vulnerable workers (0.667 and 0.294). But the estimated elasticity (column (12)) is larger (negative) for the studies that do focus on vulnerable workers $(-0.452)$. There are only four studies in this category (focus on vulnerable workers, and no other features that more strongly predict negative employment effects), and one of these has an extreme estimated elasticity $(-1.99)$.

${ }^{26}$ To be clear, standard regressions in meta-analyses usually include other types of regressors, such as for the data used, the sample size, perhaps the precision, etc.

${ }^{27}$ We also estimated meta-regressions with all the possible two-, three-, and four-way interactions of study features. Not surprisingly, given the large number of highly collinear variables, and the small number of observations in some of the cells (see Appendix Table A4), the estimates of these regressions were quite imprecise. Results are available from the authors upon request. The models in Tables 3, 4, and 5 are restricted versions of this model.

${ }^{28}$ This possibility was suggested by a reviewer.

${ }^{29}$ In addition, for the particular example of whether a study indicates that minimum wages are binding, there are plenty of estimates showing negative employment effects that do not present evidence on whether minimum wages are binding.

${ }^{30} \mathrm{He}$ also suggests effects will vary across countries depending on a variety of factors including the share of informal workers not covered, coverage of secondary workers in families, and whether minimum wage workers tend to be heads of low-income households. 